\title{
Design and validation of a sheet metal clamping system for additive manufacturing and post-processing
}

\author{
Julian Ferchow $^{1} \cdot$ Marvin Bühler $^{2} \cdot$ Marcel Schlüssel $^{3} \cdot$ Livia Zumofen $^{4} \cdot$ Christoph Klahn $^{1} \cdot$ Urs Hofmann ${ }^{1}$. \\ Andreas Kirchheim ${ }^{4} \cdot$ Mirko Meboldt $^{2}$
}

Received: 3 September 2021 / Accepted: 17 January 2022 / Published online: 28 January 2022

(c) The Author(s) 2022

\begin{abstract}
Automated clamping for post-processing of mass-customized parts is a challenging step in the laser powder bed fusion (LPBF) process chain. In this study, a novel modular sheet metal clamping system was developed that uses disposable sheet metal profiles as a universal interface for the LPBF, robotic handling, and milling processes. Based on a fundamental investigation of hybrid additive manufacturing, the sheet metal clamping system was designed to use the same interface for the LPBF and milling processes. Subsequent an end-to-end validation was performed for the entire process chain. The concept of the sheet metal clamping system gives milling tools access to a part on five to six sides. Further, the part can be accessed from the top and bottom sides, and simplifying the removal of LPBF supports. No clamping forces are induced in the LPBF part, which is especially important for filigree structures. The sheet metal clamping system's underlying concept could be adapted to automating the LPBF process chain for applications such as prosthetic dentistry.
\end{abstract}

Keywords Hybrid additive manufacturing · Laser powder bed fusion · Post-processing · Clamping · Robotic handling · Sheet metal

\section{Introduction}

Additive manufacturing (AM), which includes laser powder bed fusion (LPBF) of metals, provides a high degree of design freedom and near-net-shape production [1]. LPBF further enables mass customization with a short lead time, which is promising for many industries such as prosthetic dentistry [2-6]. However, the wide industrial application of LPBF is hindered by the low accuracy and high surface roughness of parts and the manual removal of support structures. Post-processing, including support removal and machining, accounts for up to $40 \%$ of the total manufacturing costs [7-9]. Milling is a common post-processing step to

Julian Ferchow

ferchow@inspire.ethz.ch

1 inspire AG, ipdlz, Leonhardstrasse 21, 8092 Zurich, Switzerland

2 ETH Zürich, pdlz, Leonhardstrasse 21, 8092 Zurich, Switzerland

3 Gressel AG, Schützenstrasse 25, 8355 Aadorf, Switzerland

4 ZHAW, ZPP, Lagerplatz 22, 8400 Winterthur, Switzerland realize an LPBF part with the required surface roughness and tolerance [9]. A stable milling process requires rigid clamping of the LPBF part, which has led to the development of different clamping systems such as the form-adaptive clamping jaws [10], zero-point clamping system [11], and parallel clamping jaws [12]. However, these are not ideal for complex and customized LPBF parts. For example, parallel clamping jaws must be produced as a negative shape, which is cost-intensive for customized parts at the mass scale [12]. Producing integrated parallel clamping interfaces in the LPBF process restricts the design freedom and increases the processing time [13]. Clamping jaws limit milling tools' access and require manual processes, which are costintensive and unsuitable for automation [14]. Another important drawback of clamping jaws is introducing clamping forces to an LPBF part, which is usually lightweight and optimized for a specific load case, so the additional forces are likely to deform the part. Thus, the clamping interface is a major design challenge [14].

A standardized interface for mass customization of LPBF and post-processing is necessary to tackle these challenges. The interface should facilitate the process chain's automation and require no additional build time in the LPBF 
process. Furthermore, high tool accessibility should be realized for post-processing, and no clamping forces should be induced in the LPBF part. The goal of this study is to present and validate a novel and modular sheet metal clamping system that uses disposable sheet metal profiles as a universal hybrid AM interface for the LPBF, robotic handling, and milling processes.

The sheet metal clamping system enables automated separation of the LPBF part connected to the sheet metal substrate from the base plate. It also allows the automated placement of the sheet metal interface in the milling machine and high tool accessibility for the milling process. After the milling process, the LPBF part can be separated from the sheet metal. This paper analyzes each step of the process chain and compares the new clamping system design with the state of the art. Figure 1 visualizes the main steps of the sheet metal clamping system and the corresponding sections of this paper.

This paper is structured as follows: Sect. 2 presents and discusses the tensile strength between the LPBF part and the sheet metal as well as the deformation of the sheet metal.
Section 3 presents the design of the sheet metal clamping system. Section 4 presents the validation of the sheet metal clamping system through industrial case studies. Section 5 compares the sheet metal clamping system to the current state of the art. Section 6 concludes the paper.

\section{Design considerations: tensile strength and deformation of sheet metal}

The tensile strength and the sheet metal deformation was evaluated for the hybrid connection between the LPBF part and sheet metal. Hybrid AM refers to joining a sheet metal produced by a forming process with an AM part produced by LPBF. A main challenge of hybrid LPBF is the connection zone between the sheet metal and the LPBF part for the material properties and thus the bond strength [15-17]. For this study in particular, it is important to investigate the material properties to ensure that the high loads of the milling process can be handled. Regarding the deformation of the sheet metal, the main concern is the thermal distortion during the LPBF

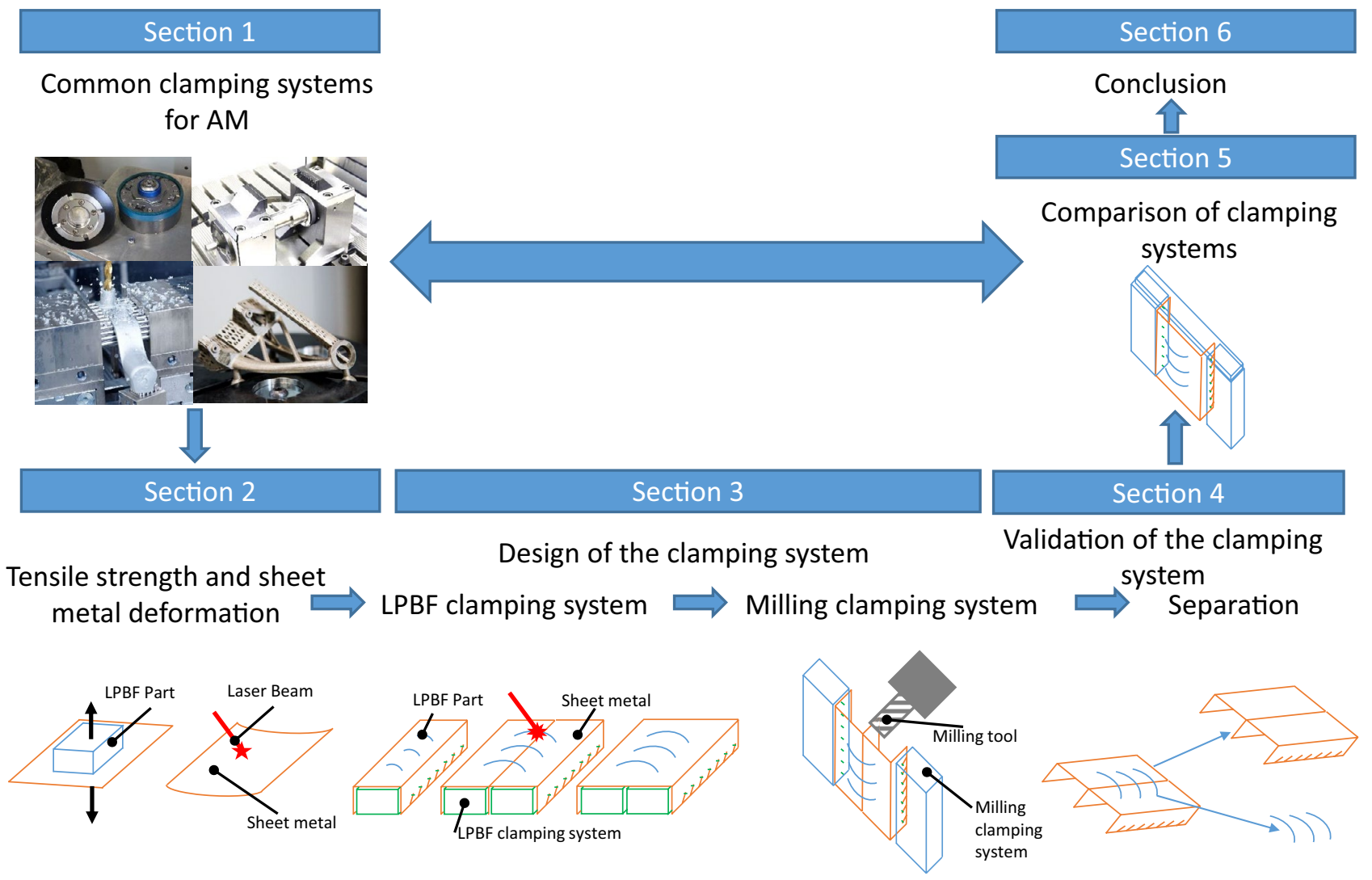

Fig. 1 Structure of the paper and conceptual process chain of the sheet metal clamping system 
Table 1 Laser parameter sets for the core

\begin{tabular}{llll}
\hline Parameter set & $\begin{array}{l}\text { Volumetric energy } \\
\text { density } E_{v d}\left[\mathrm{~J} / \mathrm{mm}^{3}\right]\end{array}$ & $\begin{array}{l}\text { Laser power } \\
P[\mathrm{~W}]\end{array}$ & $\begin{array}{l}\text { Laser } \\
\text { speed } v \\
{[\mathrm{~mm} / \mathrm{s}]}\end{array}$ \\
\hline PS 1 & 60 & 90 & 600 \\
PS 2 & 46 & 70 & 600 \\
PS 3 & 45 & 90 & 800 \\
PS 4 & 36 & 90 & 1000 \\
PS 5 & 33 & 50 & 600 \\
\hline
\end{tabular}

process due to the temperature gradient between the LBPF part and the sheet metal. The thermal distortion can cause the sheet metal to detach from the base plate, which would increase the final form deviation and cause warping. Further, warping of the LPBF part can lead to process defects because of a too thin powder layer. It can even lead to a process interruption because it damages the recoater or stops the recoating process. Therefore, the sheet metal clamping system dimensions must be designed to reduce thermal deformation based on major factors and their interactions $[18,19]$.

\subsection{Tensile strength}

Different LPBF parameter sets were tested to investigate which one achieved the highest tensile strength. The correlations among the volumetric energy density $E_{v d}\left[\mathrm{~J} / \mathrm{mm}^{3}\right]$, relative density $\rho_{\text {rel }}$, tensile strength $R_{m}$, and melt pool depth $d$ were analyzed. Table 1 compares different core parameter sets with varying volumetric energy density $E_{v d}\left[\mathrm{~J} / \mathrm{mm}^{3}\right]$. The volumetric energy density $E_{v d}$ is the average energy introduced during the exposure of a layer per material volume:
$E_{v d}=\frac{P}{v \cdot d_{h} \cdot t_{L}}$

where $P$ is the laser power, $v$ is the laser speed, $d_{h}$ is the hatch distance, and $t_{L}$ is the layer thickness. Additionally, the volumetric energy density $E_{v d}$ depends on the part orientation [20]. Since all samples in this study were printed in the vertical direction, part orientation was not considered for $E_{v d}$. A high volumetric energy density $E_{v d}$ usually increases the relative density of the LPBF part. LPBF test samples were printed on sheet metal, as shown in Fig. 2a. A Concept Laser Mlab Cusing R was used on stainless-steel 316L powder to fabricate the test samples. The Mlab is equipped with a Yb:YAG fiber laser having a wavelength of $1070 \mathrm{~nm}$, hatch distance $d_{h}$ of $0.084 \mathrm{~mm}$, laser focal diameter of $50 \mu \mathrm{m}$, and maximum laser power of $100 \mathrm{~W}$. The LPBF process was operated at a layer thickness of $t_{L}=30 \mu \mathrm{m}$. To produce a surface with low surface roughness, a laser power of $60 \mathrm{~W}$ and a scan speed of $300 \mathrm{~mm} / \mathrm{s}$ of the shell were used for all samples. The core parameters were varied. The Mlab has a building chamber with the dimensions of $90 \times 90 \times 80 \mathrm{~mm}^{3}$. For the tensile test, the universal testing machine Zwick/Roell 1474 Retro Line with a maximal load of $10 \mathrm{kN}$ was used. The tensile test was conducted with displacement control at a speed of $5 \mathrm{~mm} / \mathrm{min}$. The test setup is shown in Fig. 2b. A unidirectional tensile load was ensured by centering the sample on a conical surface. The parameter sets were investigated according to the relative density, tensile strength, and melt pool depth, as shown in Fig. 3. The relative density showed a correlation with the tensile strength. The ultimate tensile strengths of PS 1, 2, and 3 were comparable to those in the literature for hybrid parts [21]. The melt pool depth was measured at the intersection with the sheet metal, as
Fig. 2 (a) Design of the samples and (b) setup of the tensile test

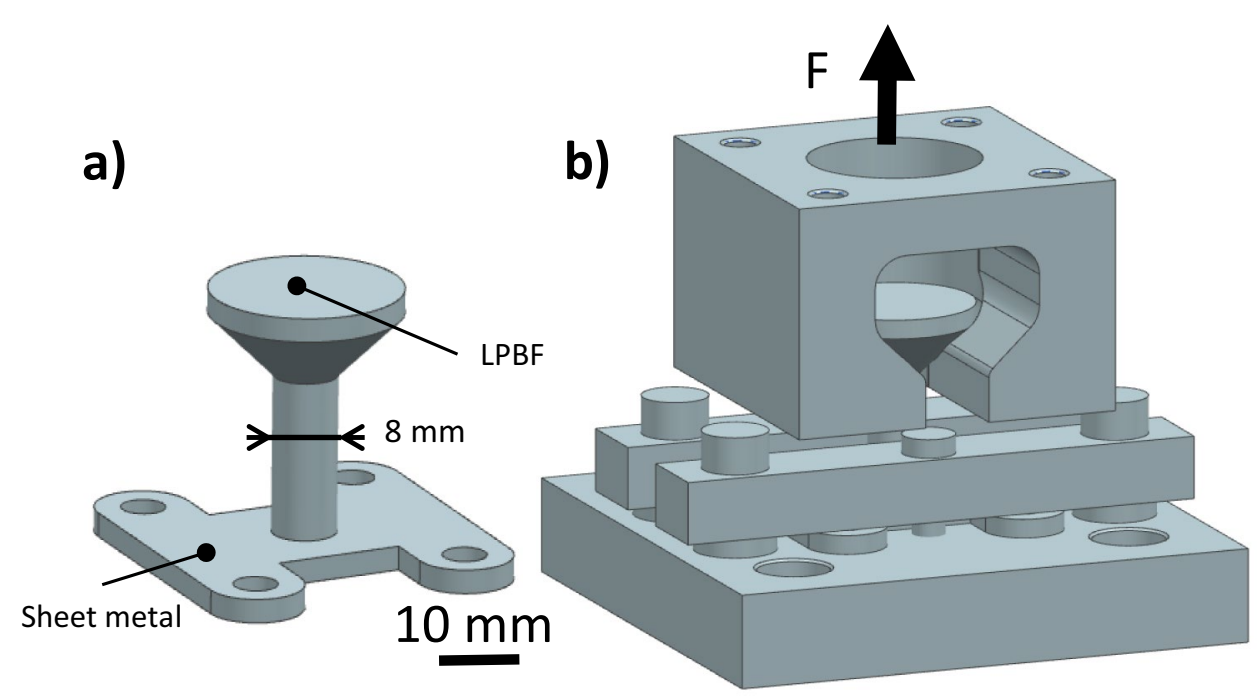



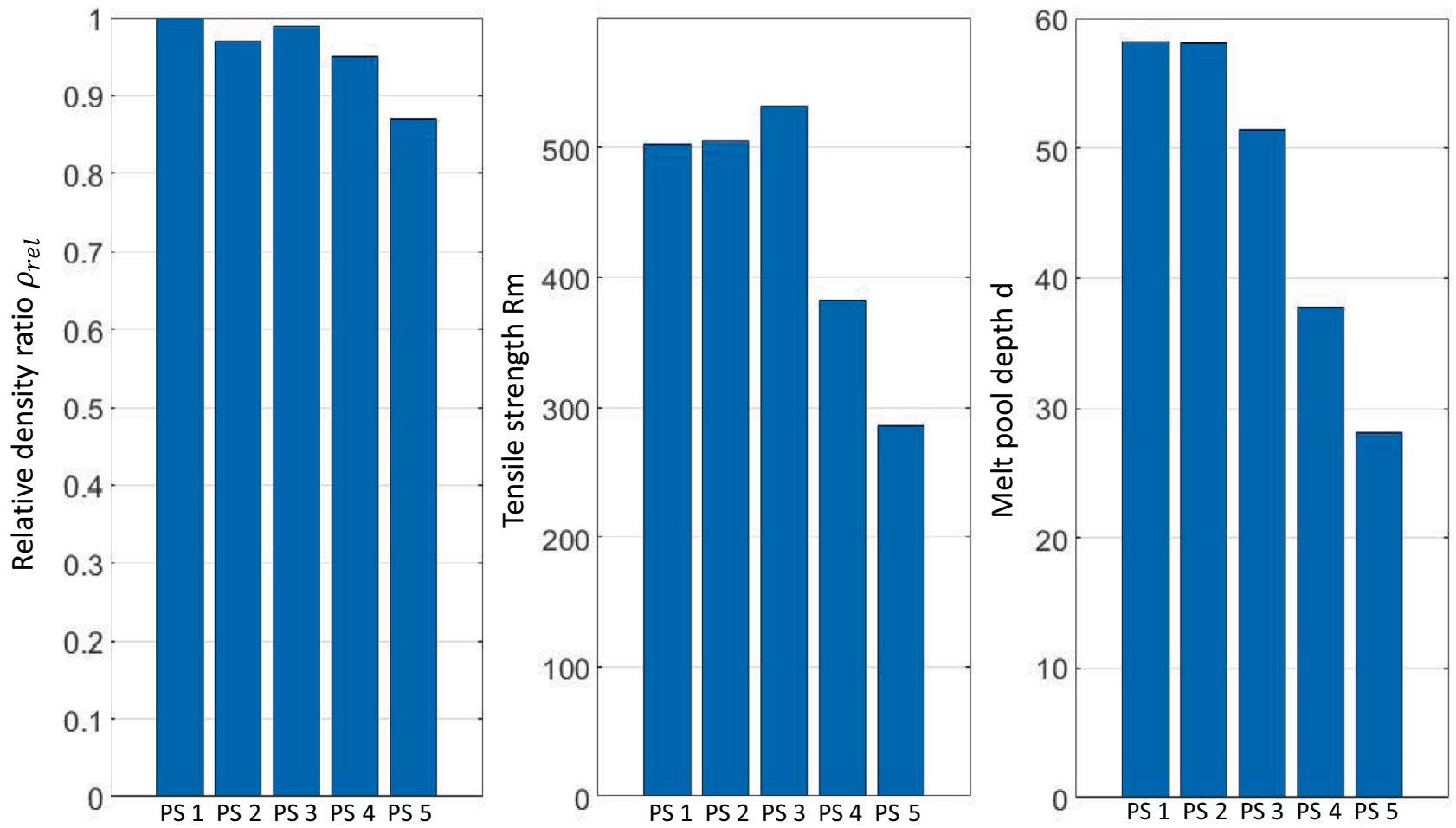

Fig. 3 Relative density ratio, tensile strength, and melt pool depth

shown in Fig. 4. The melt pool depth decreased slightly with decreasing $E_{v d}$. Because only one sample was used for each parameter set, no statistical analysis could be performed. However, a clear trend was observed: $E_{v d}$ decreased in the order of parameter sets, and the relative density ratio, tensile strength, and melt pool depth also decreased.

Figure 4 shows the polished cross-section, etched crosssection, and fracture surface of the test samples for each

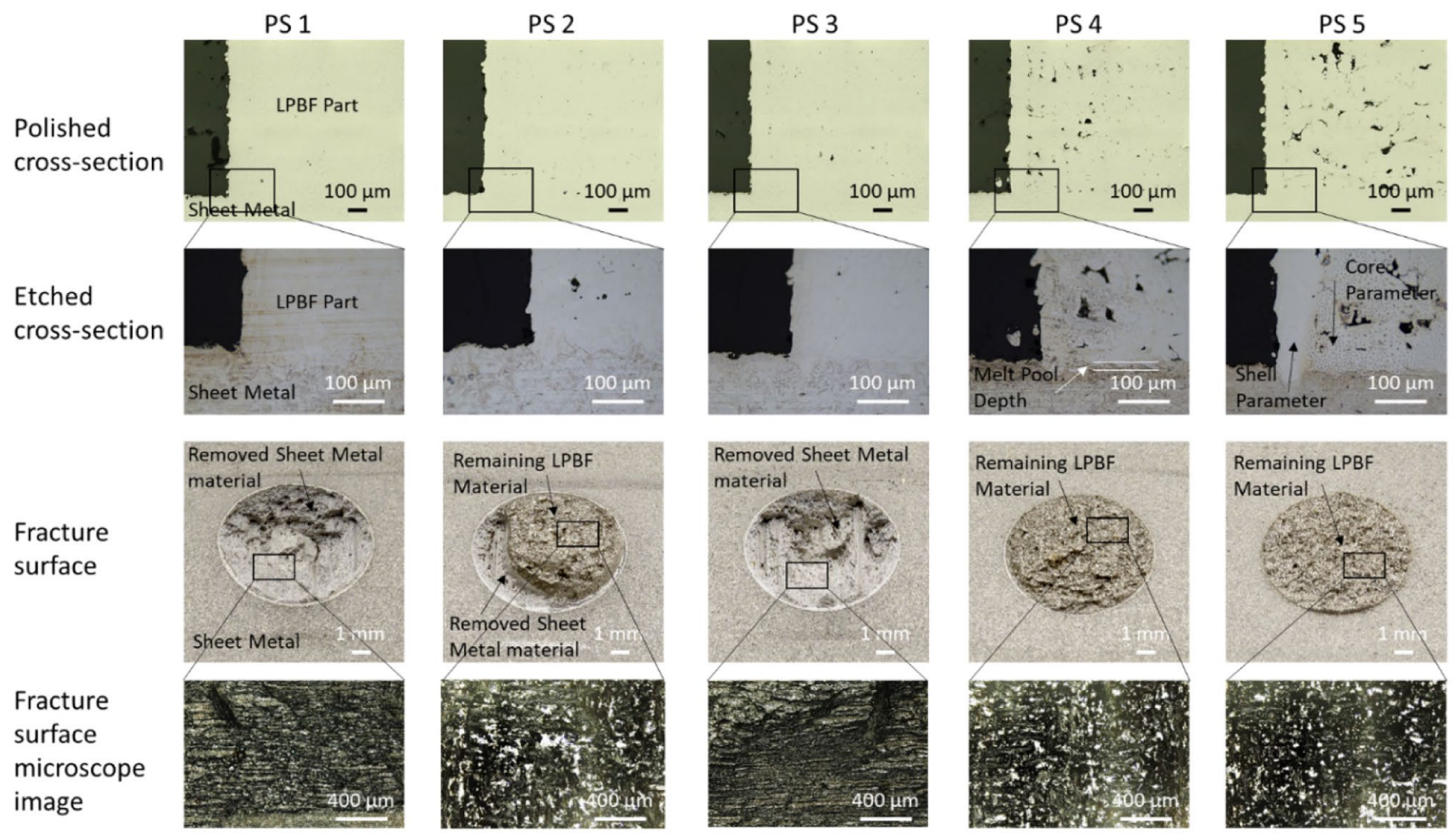

Fig. 4 Polished and etched cross-sections as well as fracture surface of the test samples 

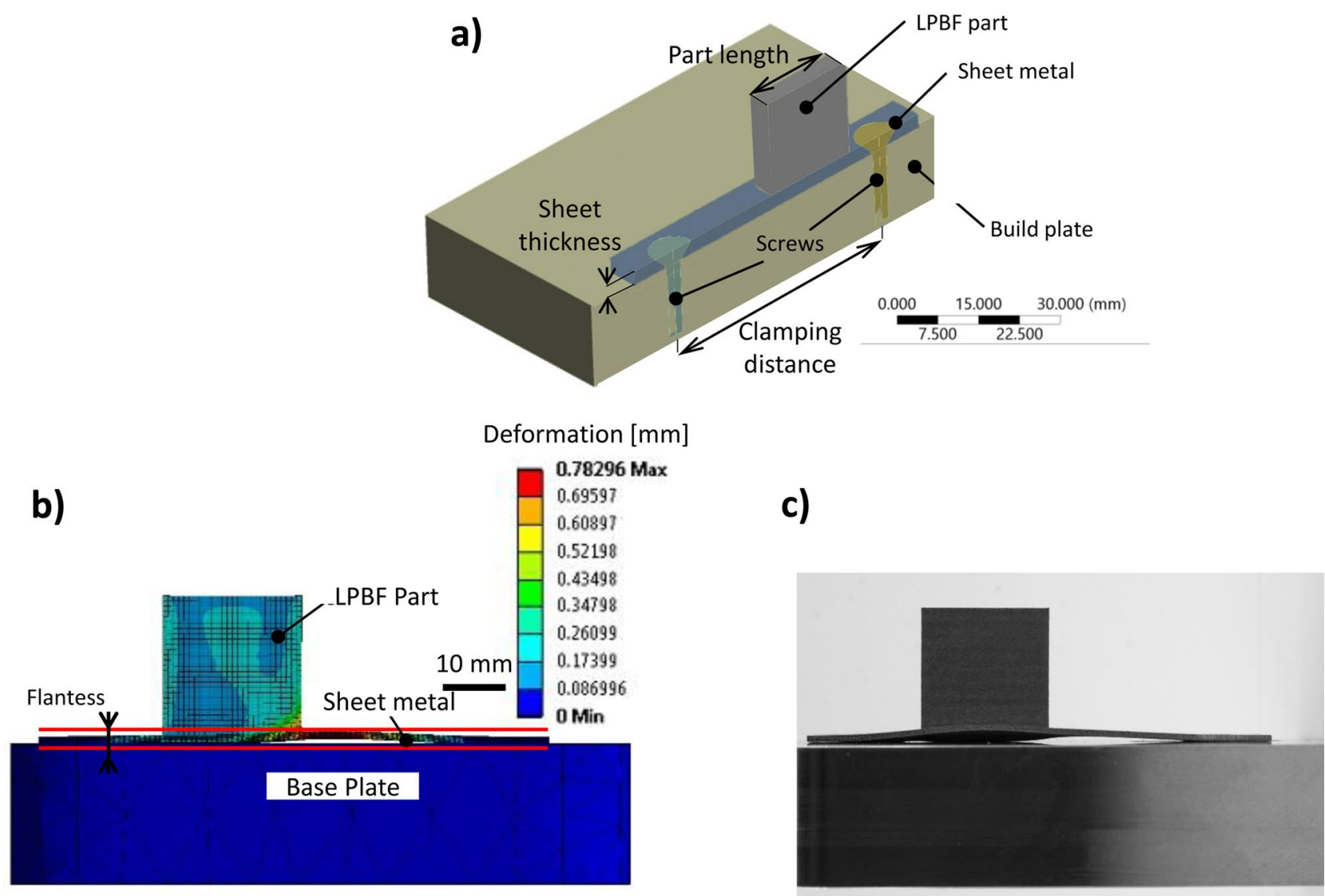

Fig. 5 Clamping system for the LBPF process: (a) simulation setup and (b) FEM deformation analysis. (c) Test sample

parameter set. In correlation with the relative density shown in Fig. 3, a lower volumetric energy density led to more pores. The fracture surface and cross-sections clearly show that the cracks propagated through the sheet metal for PS $1-3$. For PS 4 and 5, the cracks only influenced the LPBF part due to the reduced mechanical strength. The LPBF part for PS 1 broke in the sheet metal, so the LPBF part was not the sample's weakest point. Thus, PS 1 was selected because it had the highest volumetric energy density $E_{v d}$, which led to the highest tensile strength and relative density $\rho_{\text {rel }}$. The tensile strength of PS 1 is similar to a part manufactured only by LPBF [21]. Because the material broke partly or entirely in the sheet metal for PS 1-3, the connection's tensile strength was similar to that of the sheet metal's material.

\subsection{Sheet metal deformation}

A finite element simulation was performed to analyze the thermal deformation of test samples. The LPBF process was simulated with the AM Package supplied by ANSYS Workbench 2020R2. The setup is shown in Fig. 5a. Table 2 lists the simulation parameters and .
Table 3 lists the boundary conditions. The laser parameters were taken from the Concept Laser Mlab described in Sect. 2.1 with a laser power of $90 \mathrm{~W}$ and a scan speed of $600 \mathrm{~mm} / \mathrm{s}$. The simulation was performed to determine the main factors and interaction effects and the design of experiments was analyzed. Figure $5 \mathrm{~b}$ shows representative simulation results of the deformation of sample no. 2 of Table 5. In Fig. 5c, the corresponding test figure is shown. The maximum simulated flatness was $0.78 \mathrm{~mm}$ and the maximum measured flatness was $0.94 \mathrm{~mm}$. A countersunk screw of M5 was used to fix the sheet metal on the base plate. A $3^{3}$ full factorial experiment was designed based on the simulation and then applied to investigate the main factors and interaction effects of the sheet metal deformation.

Table 2 Simulation parameters

\begin{tabular}{ll}
\hline Heat convection & $10^{-5} \frac{\mathrm{W}}{\mathrm{mm}^{2} \cdot \mathrm{k}}$ \\
Ambient temperature during the build process & $50{ }^{\circ} \mathrm{C}$ \\
Cooldown temperature & $27{ }^{\circ} \mathrm{C}$ \\
Mesh size of LPBF parts and sheet metal & $0.5 \mathrm{~mm}$ \\
Mesh size of blocks & $1.2 \mathrm{~mm}$ \\
Material & $316 \mathrm{~L}$ \\
\hline
\end{tabular}


Table 3 Boundary conditions for the LPBF simulation

\begin{tabular}{ll}
\hline LPBF part-sheet metal & Bonded \\
Sheet metal-screw & Frictional, $\mu=0.3$ \\
Sheet metal-built plate & Frictionless \\
\hline
\end{tabular}

Table 4 presents the levels of the three factors: sheet metal thickness, clamping length, and part length. Table 5 presents the sheet metal deformation results.

Figure 6 shows the mean response value for each factor level. The largest difference between response values was observed for the sheet metal thickness. The sheet metal thickness was a statistically significant main factor, with a confidence level of over $95 \%$. The clamping distance and the part length showed minor effects and were not statistically significant. Figure 6 indicates that the deformation was reduced by a thickness of $3 \mathrm{~mm}$. A large difference occurred between thicknesses of 1 and $3 \mathrm{~mm}$. Thus, using a sheet metal thickness of $2 \mathrm{~mm}$ would already greatly reduce the deformation. Therefore, $2 \mathrm{~mm}$ would be a compromise between material consumption and the effect of a low deformation and therefore applicable for the clamping system design. Figure 7 shows the interaction diagram; an interaction occurs between lines that are not parallel. Interactions were observed between the sheet metal thickness and part length, clamping distance and part length, and clamping distance and sheet metal thickness. However, the sheet metal thickness was demonstrated to be the main factor for the flatness compared to the other factors. Hence, mainly the sheet metal thickness needed to be considered for the design of the sheet metal clamping system.

\section{Design of the sheet metal clamping system}

The findings presented in Sect. 2 were used to guide the sheet metal clamping system's dimensions and the sheet metal thickness. Here, the process chain of the disposable sheet metal is presented. Additionally, the design of the sheet metal clamping system is presented for the LBPF process and milling process. Finally, the support structure for the

Table 4 Factors and levels for the full factorial experiment

\begin{tabular}{llll}
\hline Factor & Level 1 & Level 2 & Level 3 \\
\hline Sheet metal thickness [mm] & 1 & 3 & 5 \\
Clamping distance [mm] & 45 & 52.5 & 60 \\
Part length [mm] & 10 & 20 & 30 \\
\hline
\end{tabular}

Table 5 Experimental results for the flatness

\begin{tabular}{|c|c|c|c|c|}
\hline No. & $\begin{array}{l}\text { Sheet metal } \\
\text { thickness } \\
{[\mathrm{mm}]}\end{array}$ & $\begin{array}{l}\text { Clamping } \\
\text { distance } \\
{[\mathrm{mm}]}\end{array}$ & $\begin{array}{l}\text { Part } \\
\text { length } \\
{[\mathrm{mm}]}\end{array}$ & Flatness [mm] \\
\hline 1 & 1 & 45 & 10 & 0.921 \\
\hline 2 & 1 & 45 & 20 & 0.994 \\
\hline 3 & 1 & 45 & 30 & 0.326 \\
\hline 4 & 1 & 52.5 & 10 & 0.820 \\
\hline 5 & 1 & 52.5 & 20 & 1.390 \\
\hline 6 & 1 & 52.5 & 30 & 1.146 \\
\hline 7 & 1 & 60 & 10 & 0.767 \\
\hline 8 & 1 & 60 & 20 & 1.728 \\
\hline 9 & 1 & 60 & 30 & 1.766 \\
\hline 10 & 3 & 45 & 10 & 0.062 \\
\hline 11 & 3 & 45 & 20 & 0.117 \\
\hline 12 & 3 & 45 & 30 & 0.054 \\
\hline 13 & 3 & 52.5 & 10 & 0.080 \\
\hline 14 & 3 & 52.5 & 20 & 0.176 \\
\hline 15 & 3 & 52.5 & 30 & 0.171 \\
\hline 16 & 3 & 60 & 10 & 0.093 \\
\hline 17 & 3 & 60 & 20 & 0.221 \\
\hline 18 & 3 & 60 & 30 & 0.270 \\
\hline 19 & 5 & 45 & 10 & 0.008 \\
\hline 20 & 5 & 45 & 20 & 0.014 \\
\hline 21 & 5 & 45 & 30 & 0.014 \\
\hline 22 & 5 & 52.5 & 10 & 0.012 \\
\hline 23 & 5 & 52.5 & 20 & 0.024 \\
\hline 24 & 5 & 52.5 & 30 & 0.031 \\
\hline 25 & 5 & 60 & 10 & 0.041 \\
\hline 26 & 5 & 60 & 20 & 0.034 \\
\hline 27 & 5 & 60 & 30 & 0.055 \\
\hline
\end{tabular}

milling process is presented. The sheet metal clamping system's basic concept is that a disposable sheet metal profile is used as an interface between the LPBF part, handling process, and clamping system. As an option, the sheet metal can be integrated with the LPBF part as a functional component. The functional combination of sheet metal LPBF components is interesting for a large range of industrial applications [22]. Using sheet metal allows large and thin-walled parts with a short lead time and low cost. In contrast, LPBF offers high design freedom, low resource utilization, and mass customization potential [15, 23]. However, up to now, the functional combination is not implemented in a large range of applications because the sheet metal was hard to clamp. The underlying concept of this clamping system can solve the clamping problem. The advantage of using cheap and disposable sheet metal is the easy handling and accessibility to the front and back sides during the milling process. The disposable sheet metal can enable automated handling and clamping. 
Fig. 6 Main factors affecting the flatness

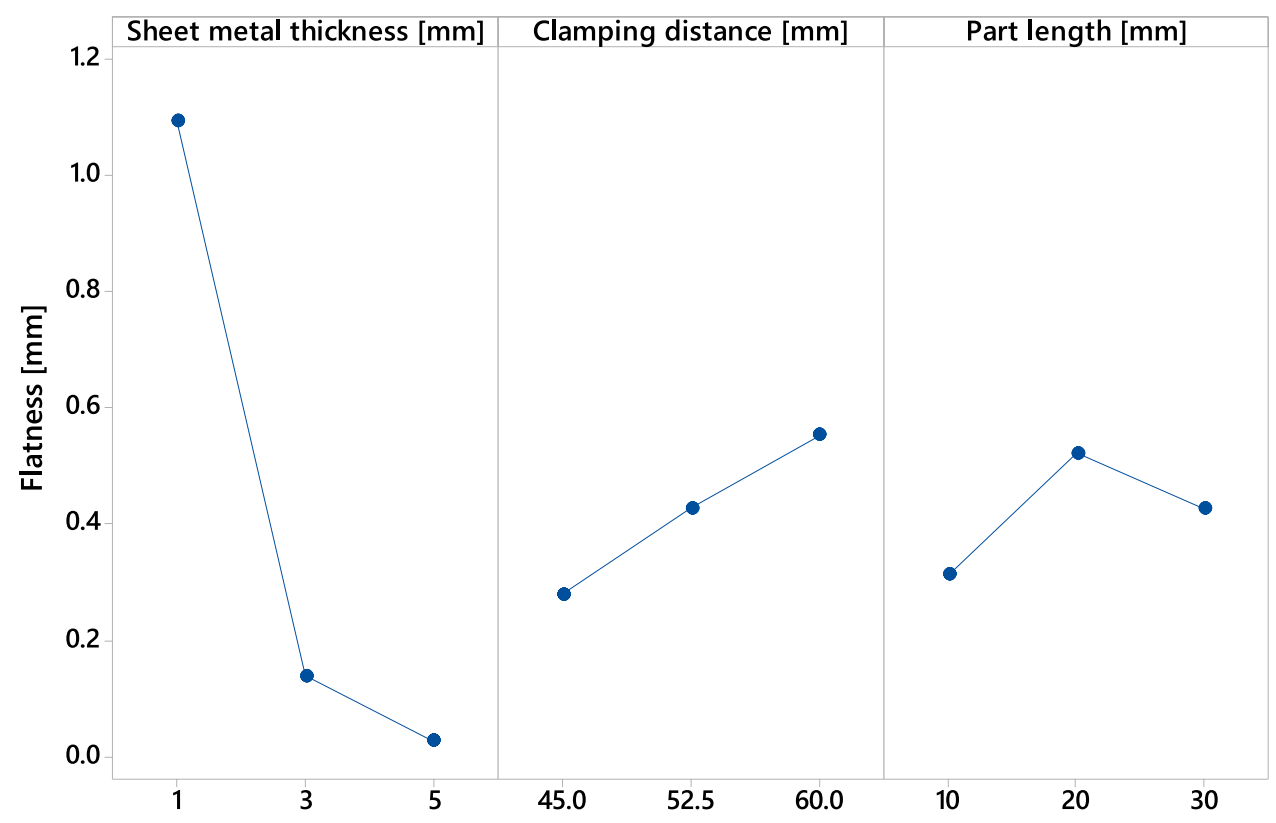

Figure 8 shows the sheet metal clamping system's design and the different process steps: (a) The sheet metal is manufactured with two different widths: 30 and $60 \mathrm{~mm}$ to accommodate different part sizes and tolerance requirements. (b) The sheet metal is then clamped for the LPBF process. (c) The LPBF part is printed on the clamped sheet metal. (d) The sheet metal is then released and removed. (e) The sheet metal is clamped to the milling machine. (f) In the milling process, the LPBF support structures are removed, and the functional surfaces of the LPBF part are treated. However, the milling supports keep the LPBF part fixed. (g) The sheet metal is released and removed, and the milling supports are removed to separate the LPBF part from the sheet metal. (h) The end products are the LPBF part and disposable sheet metal.

\subsection{LPBF process}

For the LPBF process, the sheet metal clamping system utilizes a single-use sheet metal profile and a base block that remains in the LPBF system, as shown in Fig. 9. The base block of the clamping system is modular and is fixed on the base plate. The sheet metal is fixed on the base block. The sheet metal acts as an interface and base plate for the LPBF part. Two different widths can be used for the sheet metal: $30 \mathrm{~mm}$ (narrow) and $60 \mathrm{~mm}$ (wide). The sheet metal thickness is $2 \mathrm{~mm}$ to minimize deformation
Fig. 7 Interaction diagrams of the flatness

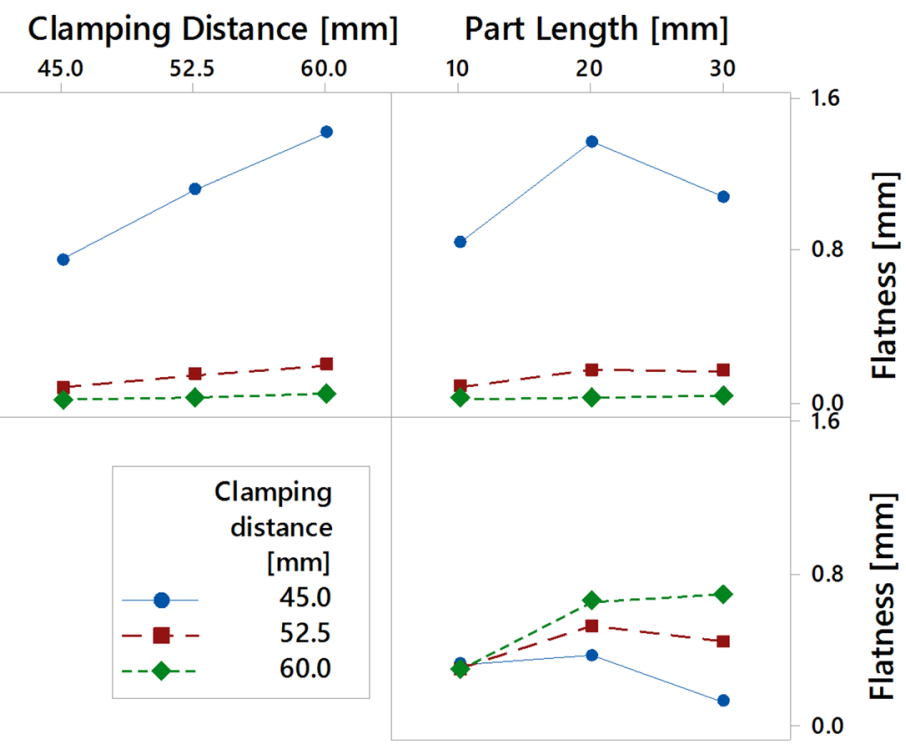




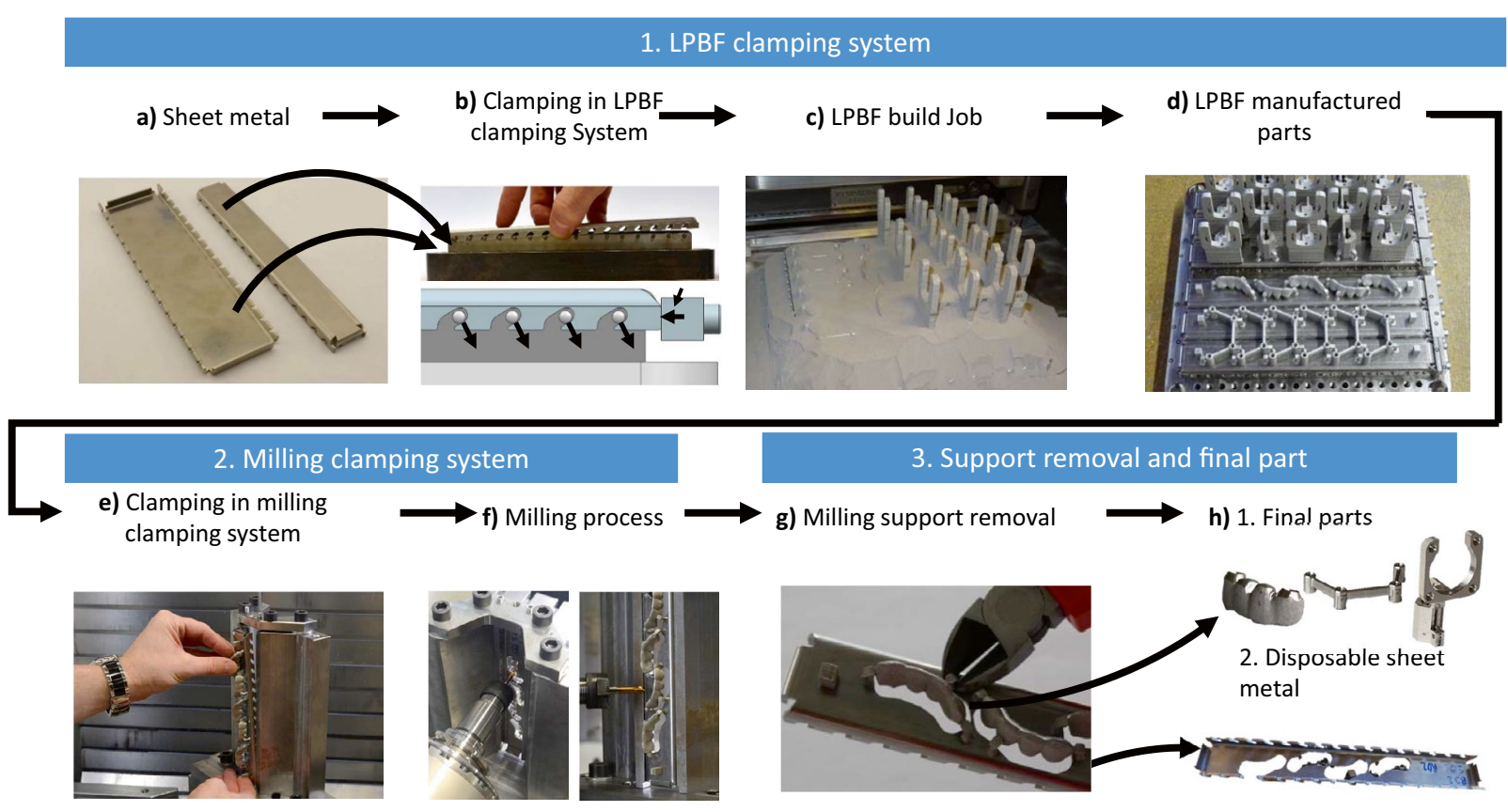

Fig. 8 Process steps of the sheet metal clamping system for the LPBF and milling processes

and material consumption, as described in Sect. 2. In this study, laser-cut and bent sheet metal was used to validate the sheet metal clamping system. In the future, disposable profiles can be mass-produced by more cost-efficient processes such as extrusion or stamping and forming. Also, the sheet metal size can be adapted to print a single LPBF part, which allows a one-piece flow for post-processing. Pins are placed on the base block's side to hold the sheet metal in an inclined groove. The closed pin-groove connection is along the entire sheet metal length. Clamping screws press the sheet metal against the clamping block. The size of the sheet metal does not limit the size of the LPBF part. The design of the sheet metal clamping system allows an overlapping LPBF part to be manufactured on the sheets. The base block is modular so that several narrow sheet metals can be fixed next to each other, or two blocks can be connected next to each other with a spacer in between, as shown in Fig. 10a. The wide sheet metal can then be clamped to the connected blocks, as shown in Fig. 10b.
Fig. 9 Concept of the sheet metal clamping system for the LBPF process a)

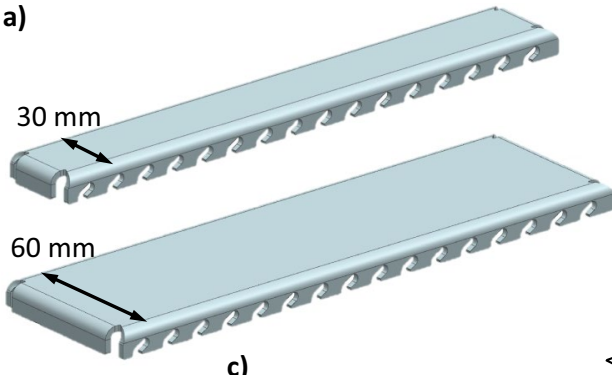

b)

Clamping Block

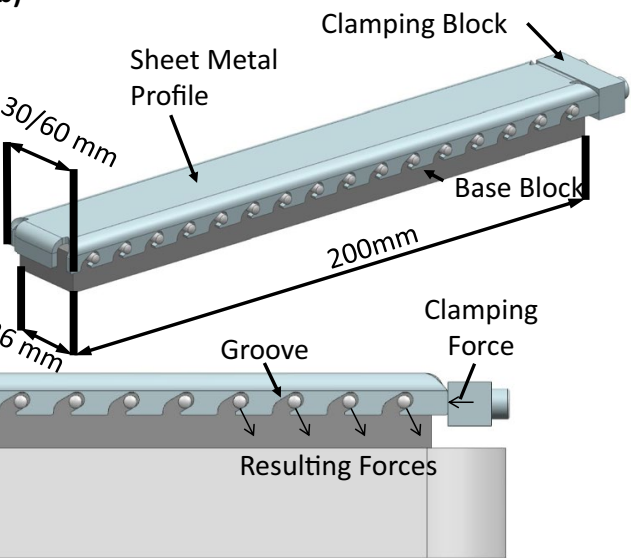




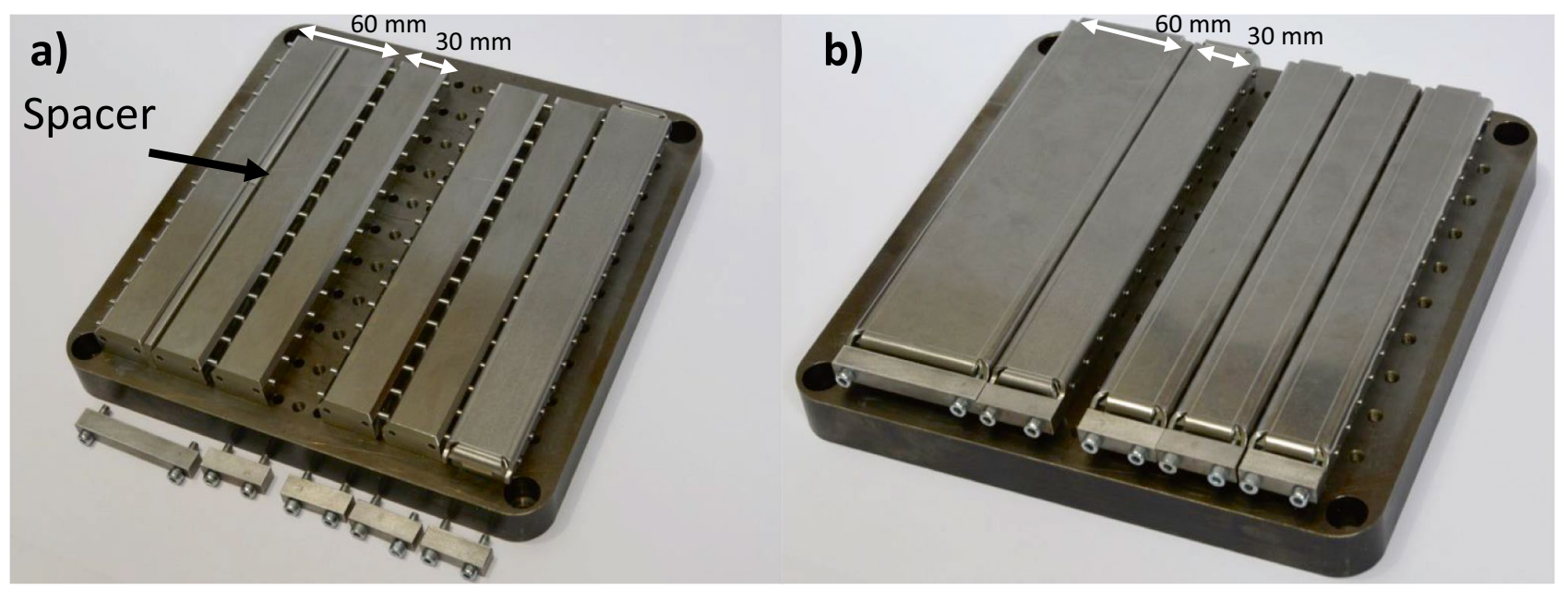

Fig. 10 Components of the modular sheet metal clamping system for the LBPF process: (a) base blocks for narrow sheet metal and assembly including the spacer for wide sheet metal; (b) system with sheet metal ready for the LPBF process

\subsection{Milling process}

After the LPBF process, the sheet metal can be removed from the LPBF system and directly clamped to the milling machine. For the milling process, the sheet metal acts as an interface to fix the LPBF part to the milling machine. Similar to the LBPF process, the sheet metal clamping system has a modular design for the milling process. Figure 11 shows the milling process for narrow and wide sheet metal. Two towers are fixed on a base block, and the distance between the towers can be adjusted according to the sheet metal width. Both towers have pins on the side. The U-frame uses screws to press the sheet metal against the pins between the towers. The towers are connected at the top by the U-frame.

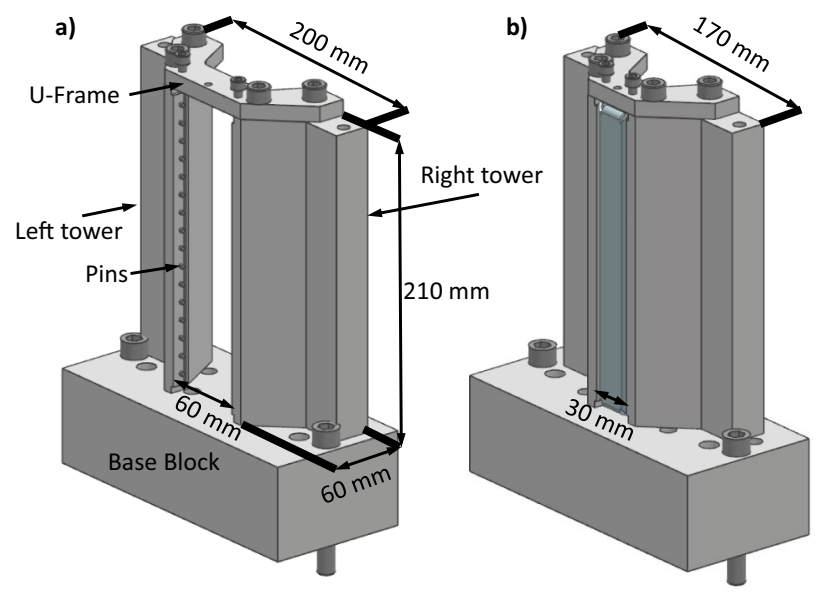

Fig. 11 Concept of the sheet metal clamping system for the milling process: (a) wide and (b) narrow sheet metal
Two screws on the U-frame press the groove of the sheet metal against the pins. Figure 12a shows the clamped sheet metal. The sheet metal clamping system's main advantage is that milling tools can reach the front and back sides of the LPBF part. Figure $12 \mathrm{~b}$ shows the tool accessibility at different orientations. Figure 13 shows the (a) front and (b) back sides of the clamped sheet metal mounted in the milling system.

\subsection{Milling support structures}

The milling support structures are manufactured during the LPBF process. They are designed to fix the LPBF part during the milling process but can be removed easily afterward. Thus, the design is a tradeoff between strong support to enable a stable milling process and a filigree structure which should be easy to remove, e.g., with pliers. Figure 14 shows the milling support structures' dimensions, and Fig. 15 shows close-up views of the milling support structures for different case studies, as discussed in Sect. 4.

\section{Validation of the sheet metal clamping system}

The sheet metal clamping system was validated end-toend for a real-world process chain through case studies of representative industrial parts. The LPBF process with the sheet metal clamping system was evaluated to verify the thermal deformation results and deviation of the part position. The behavior of the sheet metal 
Fig. 12 (a) Clamping forces and (b) milling tool accessibility a)

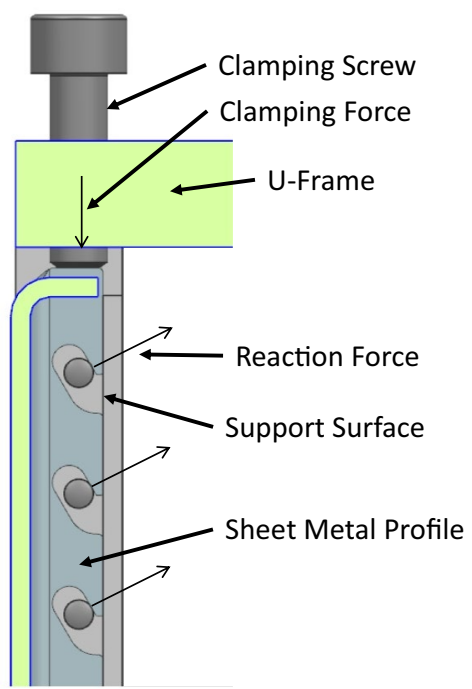

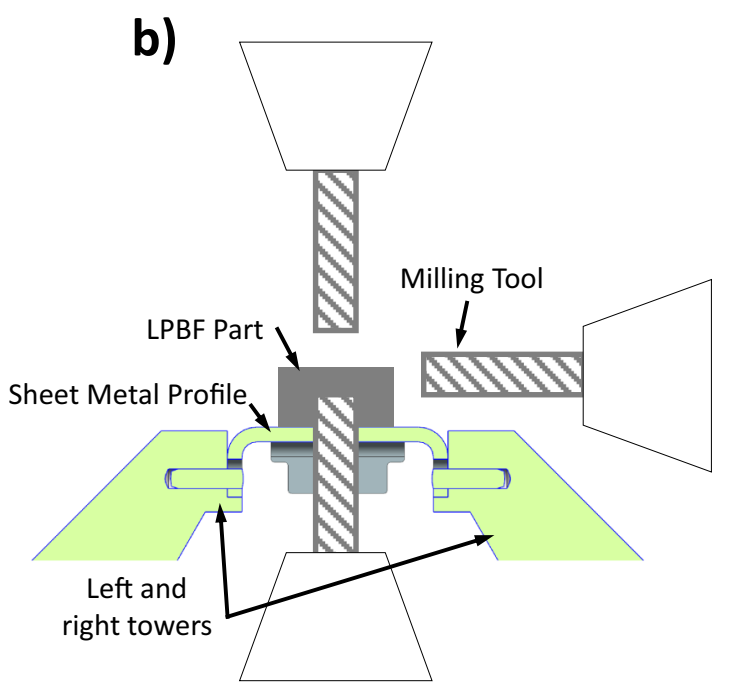

clamping system during the milling process was evaluated according to the frequency response function and surface roughness of the milled part. Finally, the residual height after the break-off test and final form deviation of the parts were measured.

\subsection{Case studies}

Five case studies were carefully selected according to applications, AM part geometries, and dimensions. Figure 16 shows the different parts and their settings in the case studies.
Figure 16a shows a cuboid with a narrow and large volume, which introduces the highest energy and thermal stress into the sheet metal during the LPBF process and leads to high deformation. The cuboid represents the worst-case scenario for the LPBF process and deformation. The cuboid was not used in the milling process because there are no specific surfaces to treat. Figure 16b shows a dental bridge with a superstructure framework representing typical small and freeform parts with filigree milling surfaces. It is retained either by two screws with a conical contact surface or by two prepared teeth abutments; therefore, small tolerances are required. Figure $16 \mathrm{c}$
Fig. 13 Sheet metal clamping system for the milling process: (a) front side and (b) back side
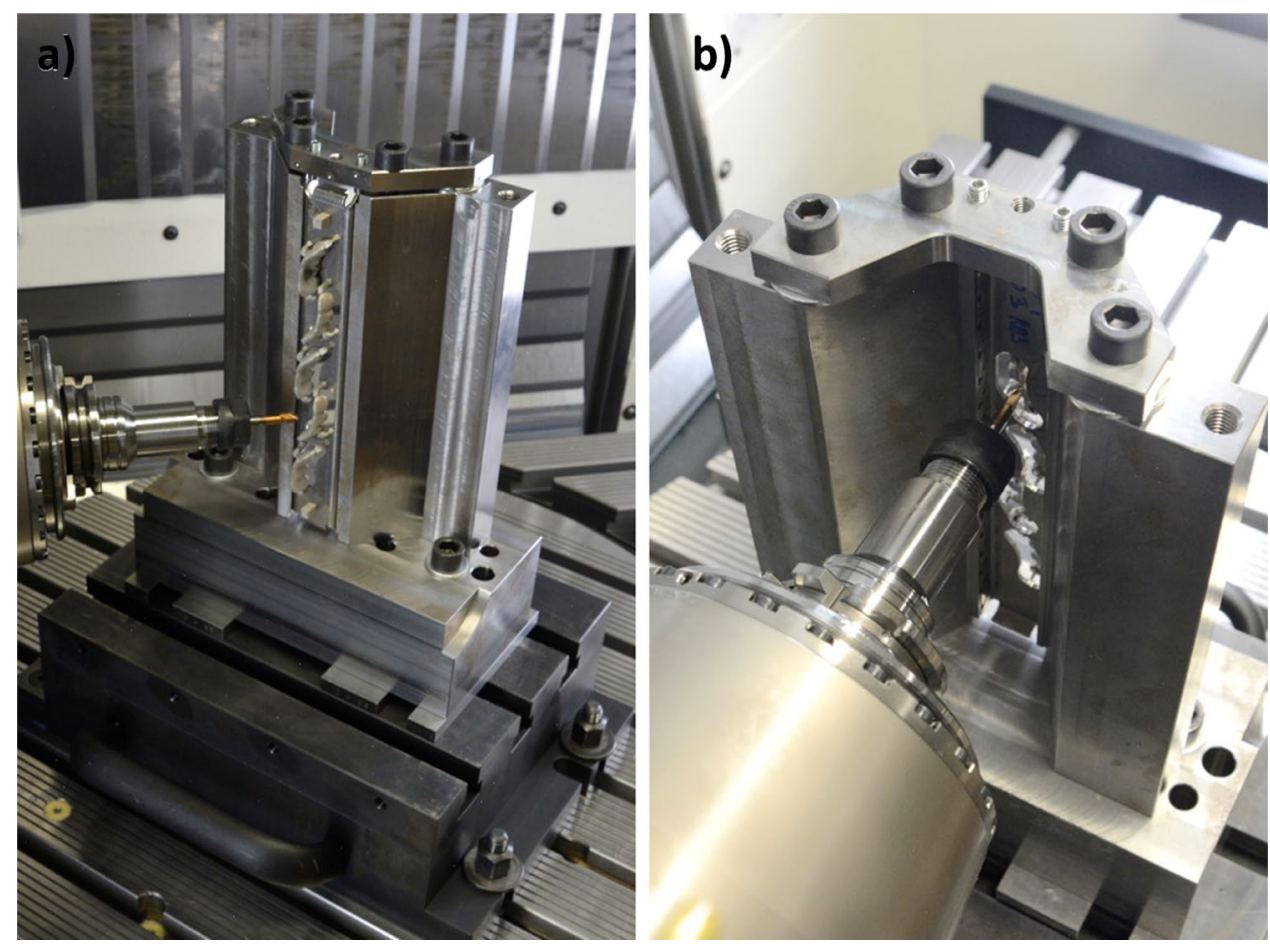
Fig. 14 Milling support structure for the dental bridge case study: (a) bottom view after milling, (b) top view after milling, and (c) dimensions of the milling support

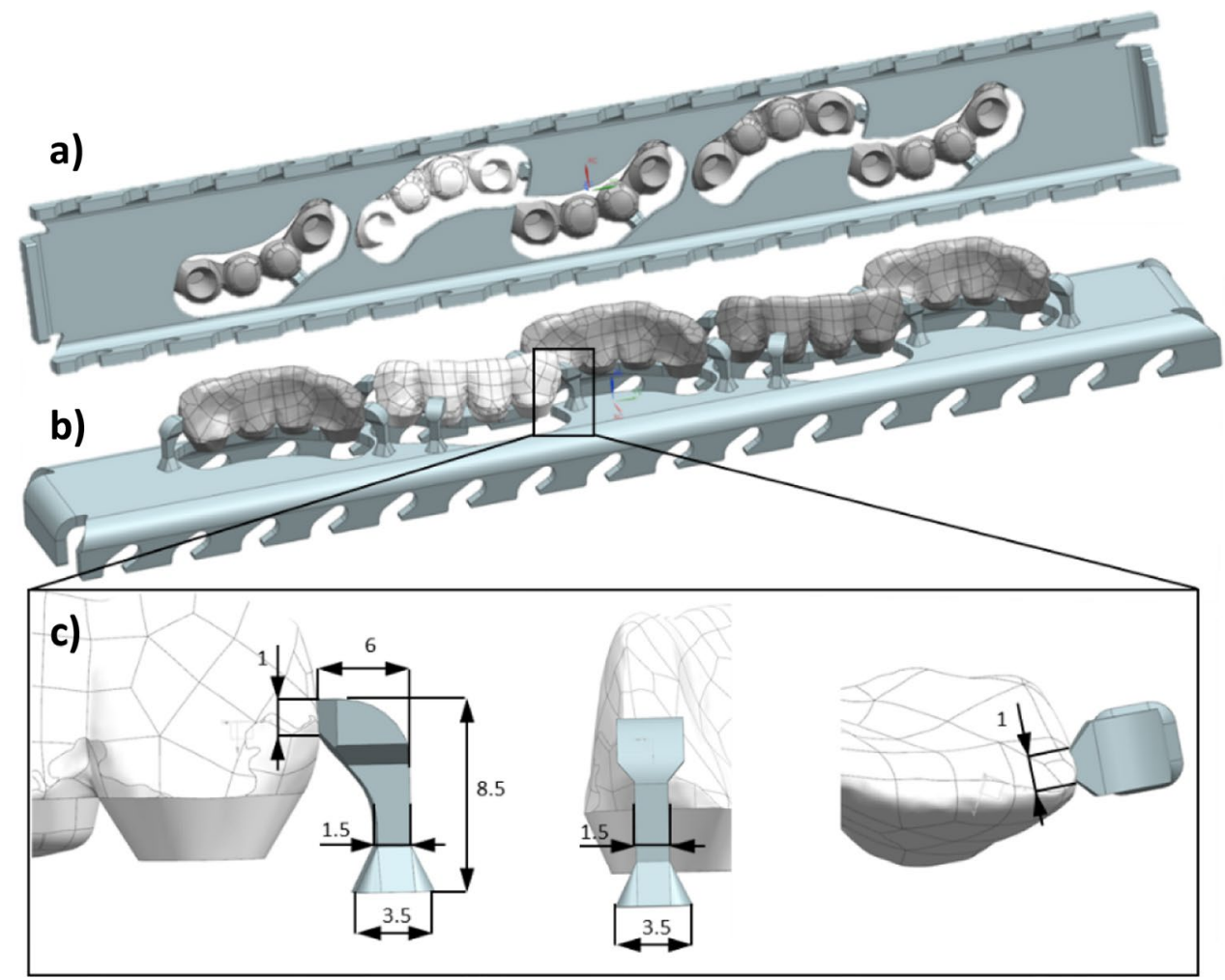

shows a dental bar, which is flat but wide. Thus, the wide sheet metal $(60 \mathrm{~mm})$ was needed. The dental bar is a superstructure framework for a toothless jaw and is retained by four screws. Two versions of the bar were manufactured. Two narrow sheets were used for the first version. The challenge was to print over the gap between the sheets without interrupting the LPBF process. For the second version, the same dental bar was printed on a wide sheet, as shown in Fig. 16d, to demonstrate the feasibility of printing and milling on the wide sheet. Both the dental bridge and dental bar require high mechanical strength to transfer the loads induced during chewing. Also, the contact surfaces between the superstructure and screw for the implant must be milled for optimal fitting. Finally, the superstructure must satisfy biomechanical and esthetic functions, so the dental bridge's superstructure is coated with a polymeric or ceramic material. The surface roughness of the LPBF part, which is covered by the coating, must not be milled because the roughness is beneficial for bonding $[5,6$, 24]. Figure 16e shows a bracket, an engineering part used to fasten to another component. The bracket is very tall in relation to the sheet metal with a large volume. This presents a particular challenge for the drilling and milling feed forces as the large lever generates a high moment in the filigree structure at the top of the part. a)

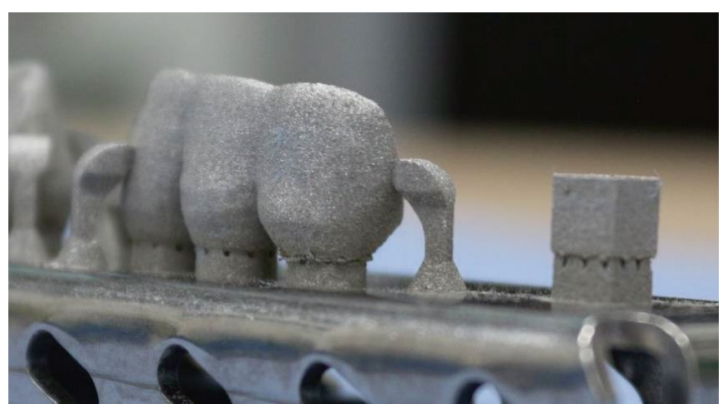

b)

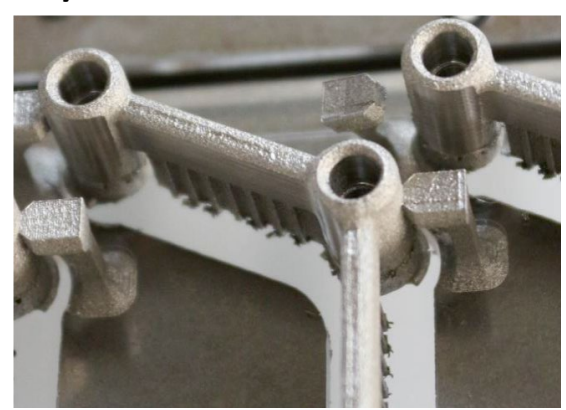

c)

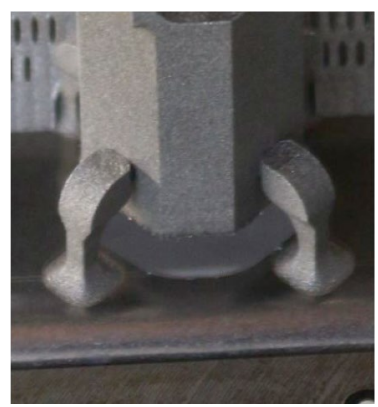

Fig. 15 Milling support structures for different case studies: (a) dental bridge, (b) dental bar, and (c) bracket 
Fig. 16 Case studies: (a) cuboid, (b) dental bridge, (c) dental bar from narrow sheet metal, (d) dental bar from wide sheet metal, and (e) bracket
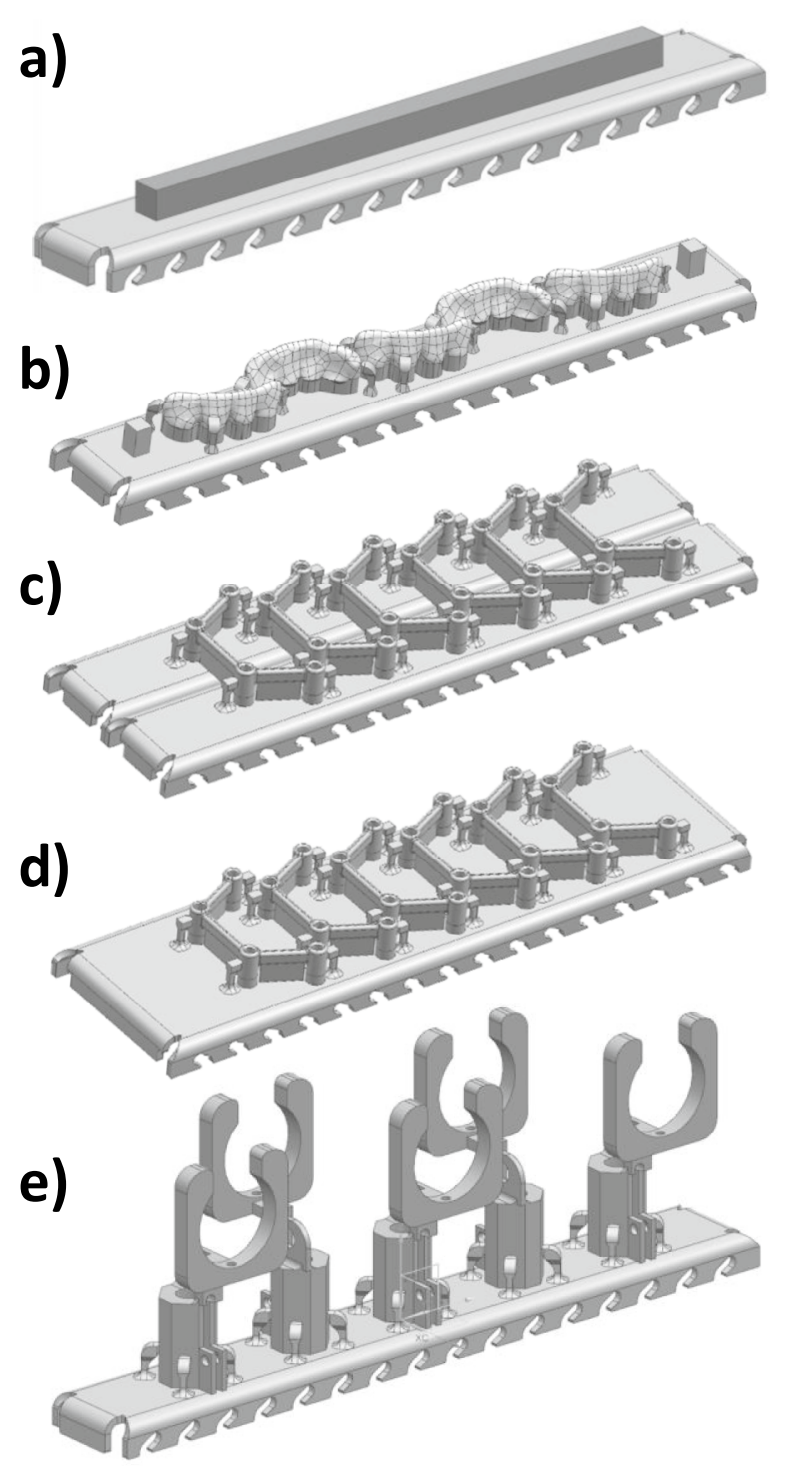
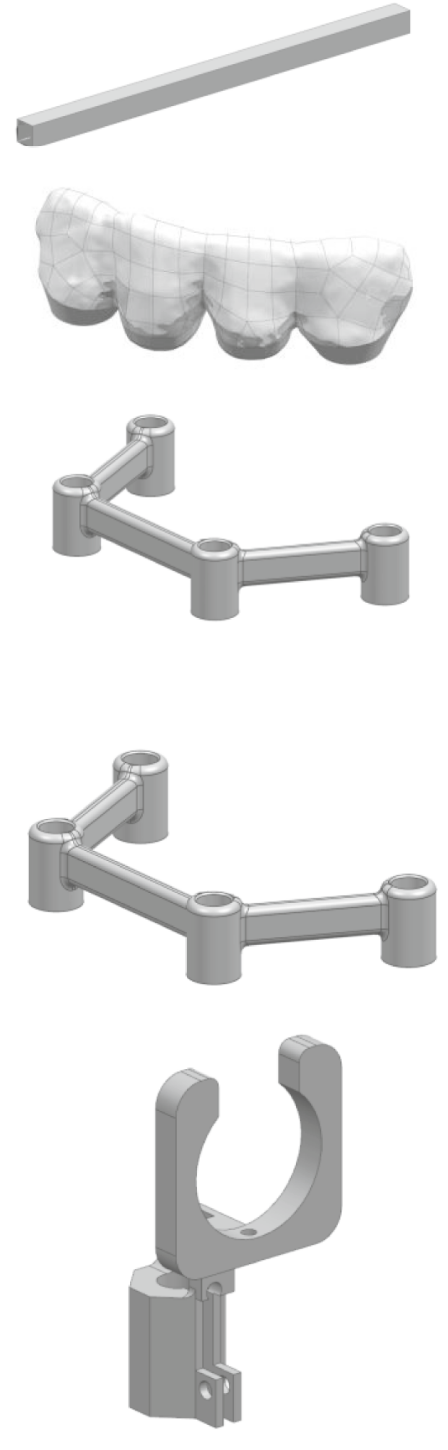

\subsection{Thermal deformation of the sheet metal in the z-direction}

A critical consideration of the LPBF process is the deformation of the sheet metal. This can lead to inaccuracy of the LPBF part and disturb the recoating process. Numerical simulations were performed to predict the LPBF part's deformations and determine whether the sheet metal clamping system can be used without disturbing the LPBF process. Critical regions can be identified to determine whether wide or narrow sheet metal is suitable. Further measures can be applied, such as increasing the thickness of the sheet metal. A Renishaw AM 400 HT was used to validate the design of the sheet metal clamping system. This is a larger machine with chamber dimensions of $248 \times 248 \times 285 \mathrm{~mm}^{3}$. It has a pulsed $\mathrm{Nd}$ :YAG fiber laser with a maximum power of $400 \mathrm{~W}$, a wavelength of $1060 \mathrm{~nm}$, and a laser spot size of $70 \mu \mathrm{m}$. The following parameters were set for the hatching: laser power of $120 \mathrm{~W}$, a scan speed of $600 \mathrm{~mm} / \mathrm{s}$, point distance of $30 \mu \mathrm{m}$, and exposure time of $50 \mu \mathrm{s}$. The hatch distance was $0.084 \mathrm{~mm}$, and the border distance was $0.02 \mathrm{~mm}$. For the contours, the laser power was set to $70 \mathrm{~W}$ with a scan speed of $300 \mathrm{~mm} / \mathrm{s}$, point distance of $15 \mu \mathrm{m}$, and exposure of $50 \mu \mathrm{s}$. The numerical simulation was performed with the same parameters used in the sheet metal deformation simulation, as given in Table 2 of Sect. 2.2. The laser power was adjusted to $120 \mathrm{~W}$ to match that of the Renishaw AM 400 HT, and the scan speed was set to $600 \mathrm{~mm} / \mathrm{s}$. The simulation setup is shown in Fig. 17, and the boundary conditions are presented in Table 6 . The GOM ATOS Core 200 3D scanner was used for scanning. The 3D measurement system was based on the optical stereo camera principle. 
Fig. 17 Setup of the simulation for the sheet metal clamping system in the LBPF process

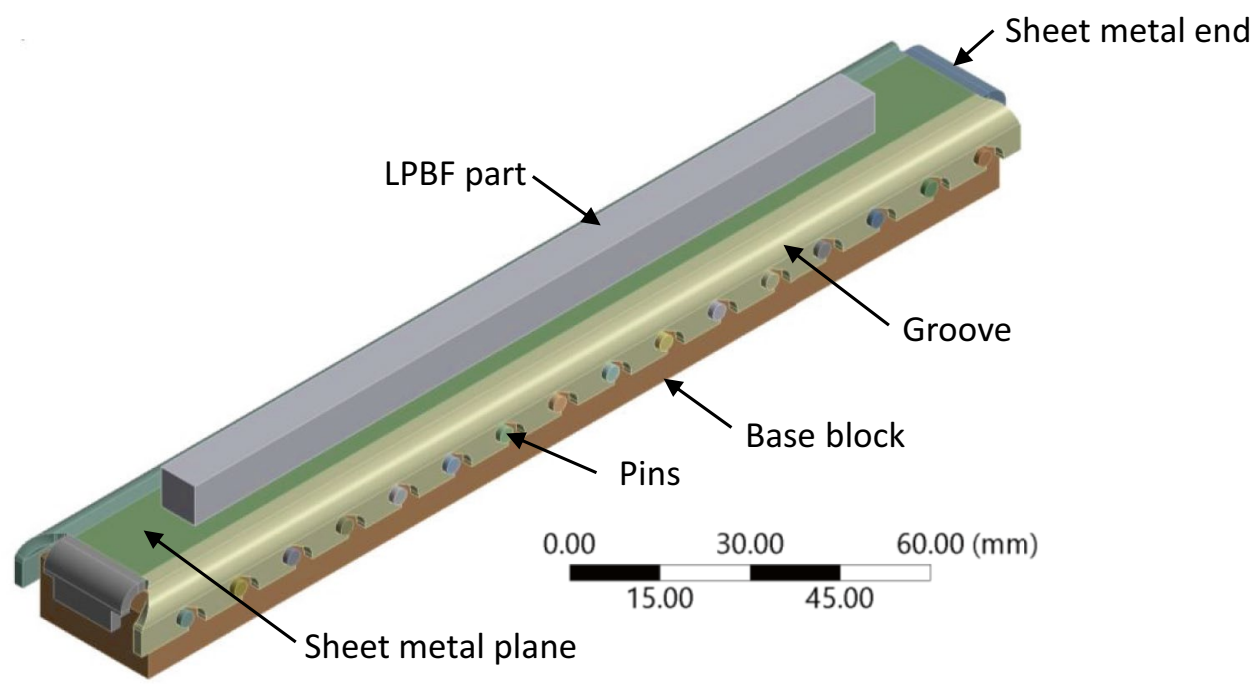

Figure 18 shows the simulation and measurement of the sheet metal deviation from the computer-aided design (CAD) drawing in the clamped condition after the LPBF process. The simulation and measurement results were compared, and the regions with high and low deformations corresponded. To better differentiate the deviation, Fig. 18 shows different scales for each case study. As expected, the largest deformations were observed at the end of the cuboid, where the maximum simulated and measured values were 0.46 and $0.37 \mathrm{~mm}$, respectively. The difference between the measured and simulated deformations was attributed to the simulation's complex boundary conditions and the manufacturing tolerances of the sheet metal. Despite the differences between the simulation and measurement, the simulation does show trends that can be used to identify critical areas before the LPBF process is started.

Large deformation of the sheet metal can lead to a large deviation of the LPBF part from the tolerance. To evaluate the clamping system's effect on the part tolerance, the sheet metal flatness needed to be monitored at different process steps. The flatness represents the minimum and maximum distances between two parallel planes [25]. Figure 19 shows the sheet metal's flatness when clamped after different process steps based on 3D scans. Clamping smoothed the sheet metal from previous processes by $44 \%$ on average for all case studies. The average deformation of the clamped sheet metal increased by $23 \%$ before and after the LPBF process. The deformation increased by $500 \%$ after the LPBF process when the clamps were released because of the released residual stresses. The deformation was then reduced by $61 \%$ on average when the sheet metal was clamped again for the milling process. The maximum deformation of the clamped sheet metal during the milling process was $1.24 \mathrm{~mm}$. Therefore, the clamped sheet metal's average deformation before milling was $48 \%$ greater than that of the clamped sheet metal during LPBF. Overall, the cuboid showed the highest deformation when unclamped after LPBF and clamped before milling. Due to the fact that the cuboid had the highest and most connected printed volume and area without a support structure. These deformations were investigated without considering heat treatment. As a next step, the same investigations should be performed with heat treatment, which would reduce the residual stresses that caused the high deformation after the clamping was released. The deformation in the clamped position before milling could be reduced through heat treatment.

\subsection{Deviation of the part position in the $x-y$ direction}

The maximum deviation of the part position from the CAD drawing is important for position detection during the milling process. Because of the sheet metal's thermal expansion from the measurement point, the largest deviations occur farthest from the clamping point. The deviations in the $x$ and $y$-directions of the boundary box were measured and compared to the CAD drawing for each case study.

Figure 20 shows the maximum deviations after each process step. After the LPBF process with the sheet metal clamping system, the average maximum deformations were

Table 6 Boundary conditions for the simulation

\begin{tabular}{ll}
\hline LPBF part-sheet metal & Bonded \\
Sheet metal groove-pin & Frictional, $\mu=0.2$ \\
Sheet metal plane-base block & Frictional, $\mu=0.2$ \\
Pin-base block & Bonded \\
\hline
\end{tabular}


Fig. 18 Flatness of the top plane of the sheet metal in the clamped position after the LPBF results: (a) numerical simulation and (b) 3D scans of the case studies

\section{a) Simulation}
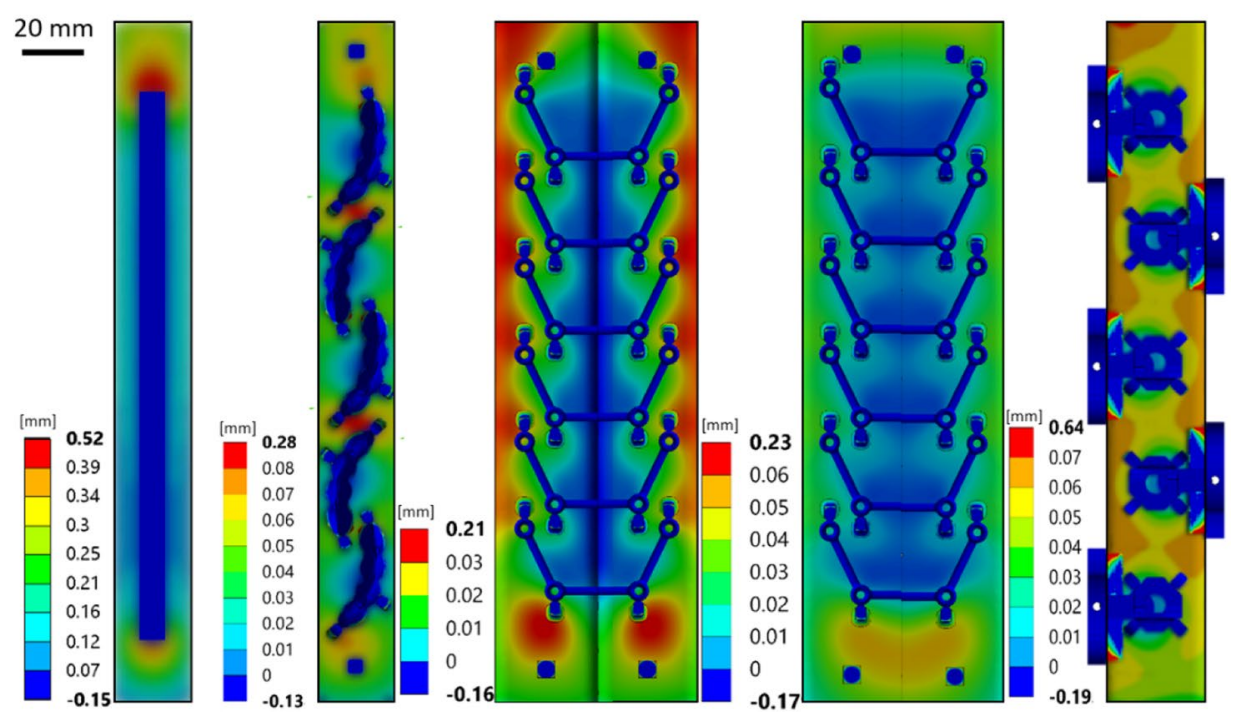

b) $3 \mathrm{D}$ Scan
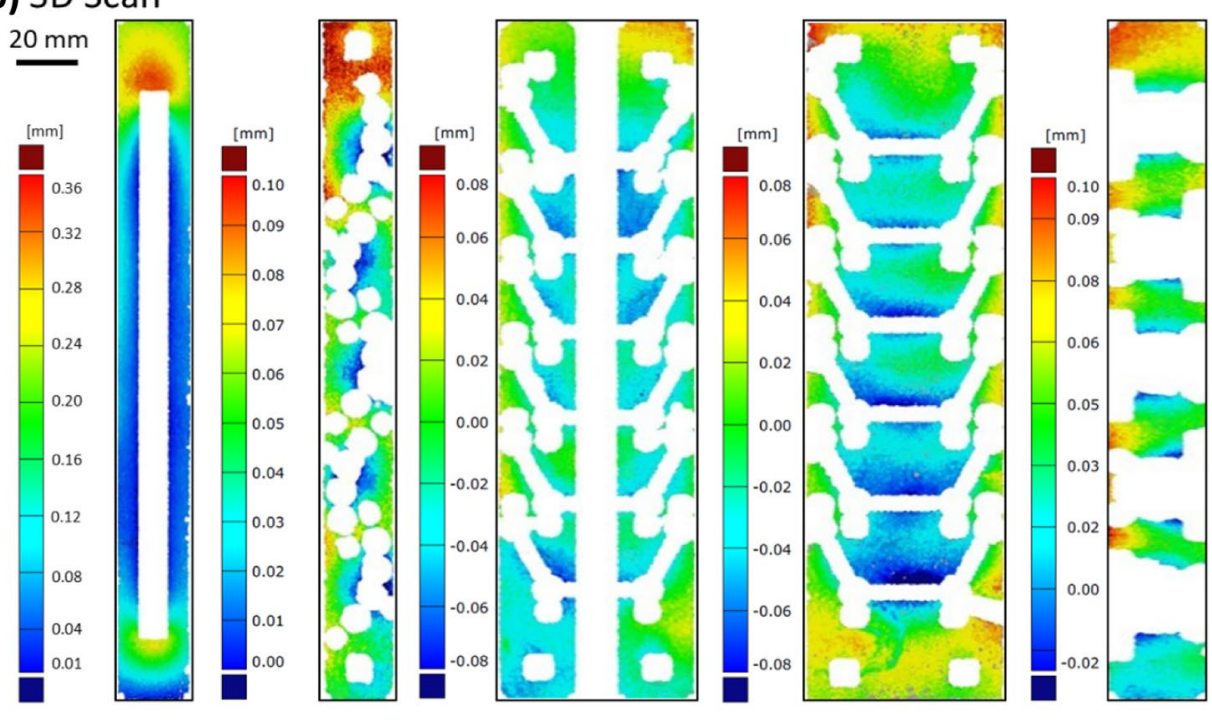

$0.034 \mathrm{~mm}$ in the $x$-direction and $0.165 \mathrm{~mm}$ in the $y$-direction. The overall maximum deviation before the milling process was $0.23 \mathrm{~mm}$. The average maximum deviations between the clamped positions after the LPBF process and before milling were $32 \%$ in the $x$-direction and $27 \%$ in the $y$-direction. The larger distances and therefore greater thermal deformations in the $y$-direction led to greater deformations of LPBF parts than in the $x$-direction. The absolute maximum deviation in the milling process was $0.23 \mathrm{~mm}$. These results demonstrate the need for position detection to facilitate the milling process.

\subsection{Dynamic compliance}

A stiff clamping system with low dynamic compliance is required for a stable milling process without chattering.
A frequency response function was created to investigate the sheet metal's dynamic stability in different case studies. The LPBF parts were excited with an impact hammer (Type 9722A500, Kistler). A piezoelectric charge accelerometer (Type 4393, Brüel \& Kjær) was used to measure the response. A signal acquisition box recorded the excitation and response signals. Finally, the frequency response function was calculated from the acquired data. Figure 21 shows the frequency response functions for the different case studies and the corresponding measurement setup. The measurements were performed before the milling process. The dynamic compliances of the LPBF part, LPBF support structure, and sheet metal were measured.

The dominant natural frequency peak for the bracket was at $1600 \mathrm{~Hz}$ with an amplitude of $0.11 \mu \mathrm{m} / \mathrm{N}$. The dental bridge's three dominant frequency peaks were smaller 
Fig. 19 Flatness at different process steps

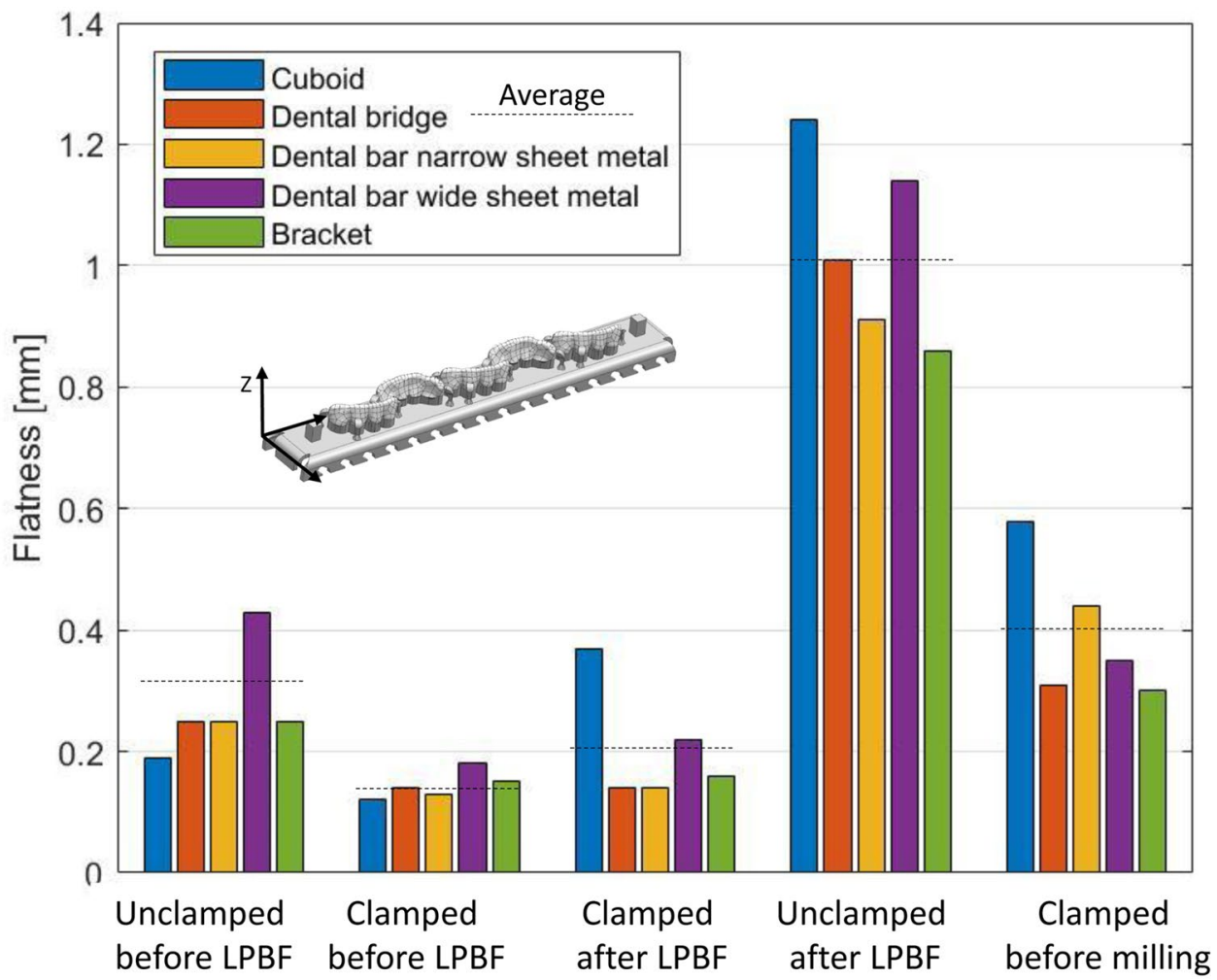

but occurred at 500, 1600, and $2200 \mathrm{~Hz}$ with a maximum amplitude of $0.035 \mu \mathrm{m} / \mathrm{N}$. The different amplitudes for the dental bridge and bracket were probably due to their different dimensions. The bracket had a large lever, which increased the amplitude, while the dental bridge was a small part. The dominant natural frequency peak for the dental bar on a wide sheet was at $2800 \mathrm{~Hz}$ with an amplitude of $0.75 \mu \mathrm{m} / \mathrm{N}$. The dominant relevant frequency peak of the dental bar bridging two narrow sheets was at $1900 \mathrm{~Hz}$ with an amplitude of $0.5 \mu \mathrm{m} / \mathrm{N}$. The dental bar on the two narrow sheets was more stable along the length axis ( $y$-direction) because it had a higher inertia moment than the single wide sheet. However, the narrow sheets were less stable along the transversal axis $(x$ direction) because of the lower bending stiffness caused by the sheets' gap.

\subsection{Milling roughness}

The surface roughness after milling was measured on a face and side for each case study, except the cuboid. The final surface roughness of each LPBF part with the sheet metal clamping system was compared to the surface roughness of a rigid block clamped with a standard parallel clamping jaw. The milling experiment was conducted with a five-axis CNC milling machine (DMU 60 monoBlock from DECKEL
MAHO). Cooling lubricant (B-Cool 755 from Blaser SwisslubeAG) was used. Because of the freeform surfaces, different end mills, ball mills, and roughing mills were used. The roughness was measured with a confocal 3D laser scanning microscope (Keyence VK-X200K) having a $z$-direction resolution of $0.5 \mathrm{~nm}$ and a Gaussian filter. The surface roughness measurements are plotted in Fig. 22. The surface roughness of the LPBF parts with the sheet metal clamping system was slightly greater than that of the rigid block. The maximum measured roughness of LPBF parts with the sheet metal clamping system was $\mathrm{Ra}=2.8 \mu \mathrm{m}$. Despite the rougher surface, $\mathrm{Ra}=2.8 \mu \mathrm{m}$ is sufficient for a large range of end-user applications. Despite the dominant peaks observed with the dynamic stability measurements, the milling roughness experiment showed minor chatter marks. The results showed that the milling parameters should be adjusted to avoid the eigenmode and chatter marks caused by the sheet metal clamping system.

\subsection{Milling support break-off test}

The LPBF part is connected to the sheet metal by solid milling supports and block supports commonly used for LPBF. The LPBF supports are removed during the milling process. The LPBF parts are removed in two steps from the sheet metal after milling, as shown in Fig. 23. First, 
Fig. 20 Maximum deviation from the CAD drawings of different case studies after each process step

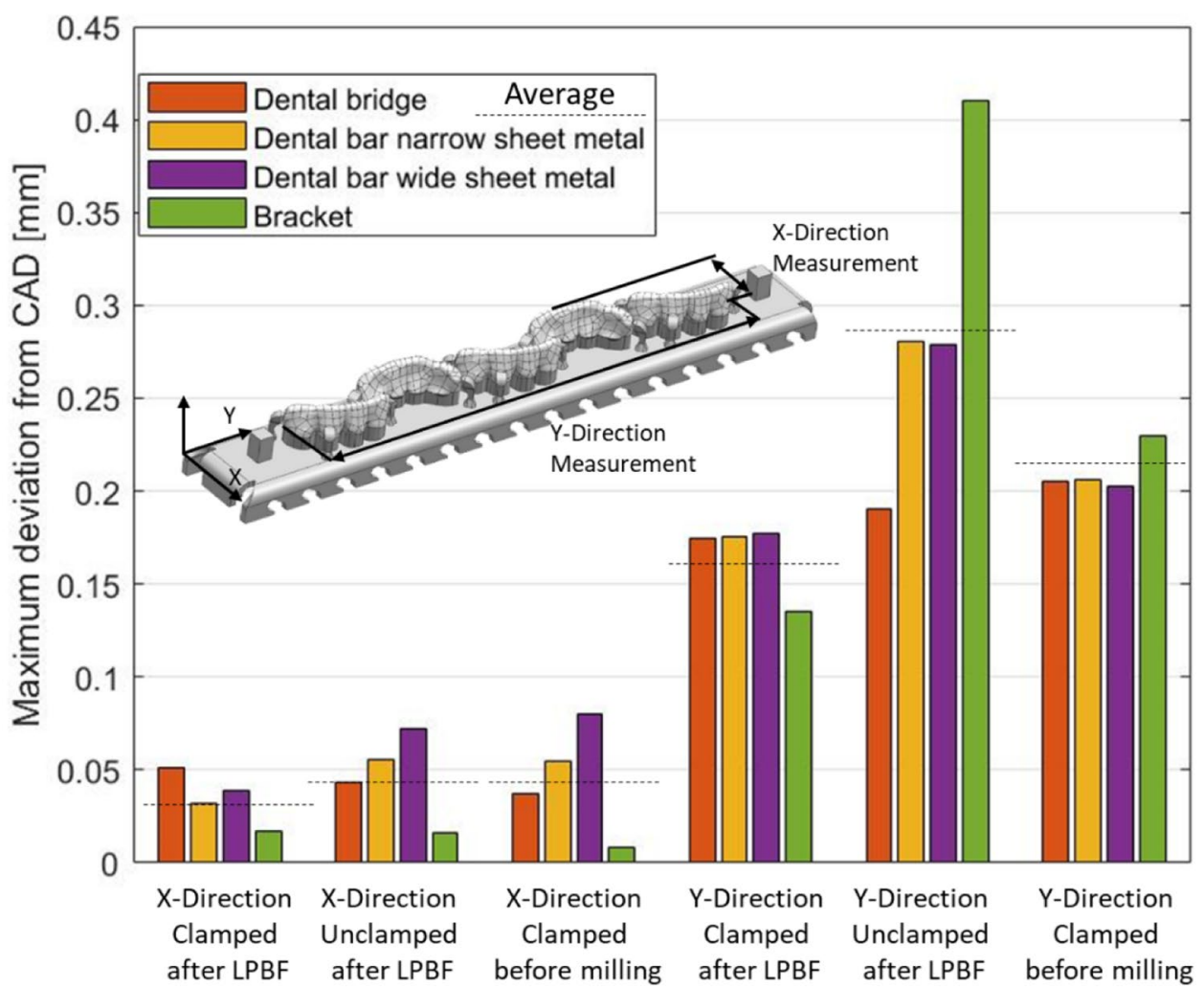

the milling supports are cut from the sheet metal with a side cutter. Second, the remaining milling supports are removed with pliers. The residual height of the remaining milling supports after the LPBF part was removed is plotted in Fig. 23. The maximum residual height was $0.297 \mathrm{~mm}$, and the average residual height for all parts was $0.14 \mathrm{~mm}$. The remaining residual height was deemed acceptable for parts with a nonfunctional surface at this position. The milling supports should be positioned on nonfunctional surfaces. If the placement on a functional surface is unavoidable, then a simple manual grinding can remove the remaining material.
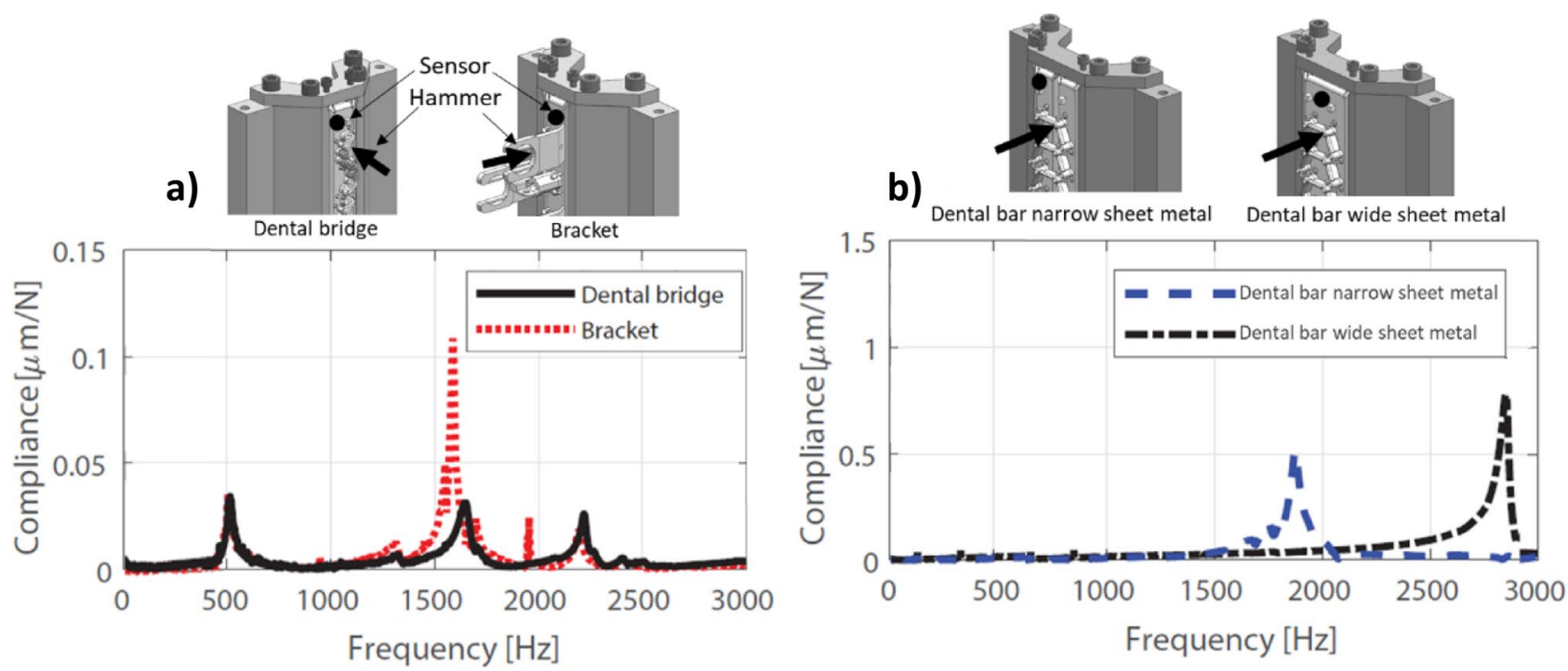

Fig. 21 Frequency response functions of the different test samples 


\subsection{Deviations of the final form}

The local form deviations of the case studies were measured after post-processing, as shown in Fig. 24. The dental bridge had a maximum deviation of $-0.32 \mathrm{~mm}$ on the as-built surface and $0.07 \mathrm{~mm}$ on the milled surface. The dental bar on two narrow sheets had a maximum deviation of $0.08 \mathrm{~mm}$ on the as-built surface and $0.04 \mathrm{~mm}$ on the milled surface. The dental bar on a single wide sheet showed less deformation than the bar on narrow sheets but also a local maximum deformation of $0.08 \mathrm{~mm}$. The bracket had a maximum deviation of $-0.6 \mathrm{~mm}$ on the as-built LPBF surface, which was attributed to thermal stresses and strong forces acting on the LPBF part when two holes were drilled. For all case studies, the maximum deviation of the milled surface was $0.08 \mathrm{~mm}$. The form deviations were mainly caused by deviations of the part position, as discussed in Sect. 4.3. An offset of $0.2 \mathrm{~mm}$ was used for the milled surfaces. A larger offset with a value of $0.5 \mathrm{~mm}$ is recommended to achieve tolerances for the final part in the future. However, the final form deviations resulting from the sheet metal clamping system are acceptable for many end-user applications.

\section{Comparison of clamping systems}

Various clamping solutions are commercially available. These were compared to the sheet metal clamping system according to selected relevant quality factors. The selection of relevant clamping systems and quality factors and their evaluation were conducted in a workshop. Nine people with different backgrounds were carefully selected to cover necessary topics of the AM clamping system: a clamping system manufacturer,

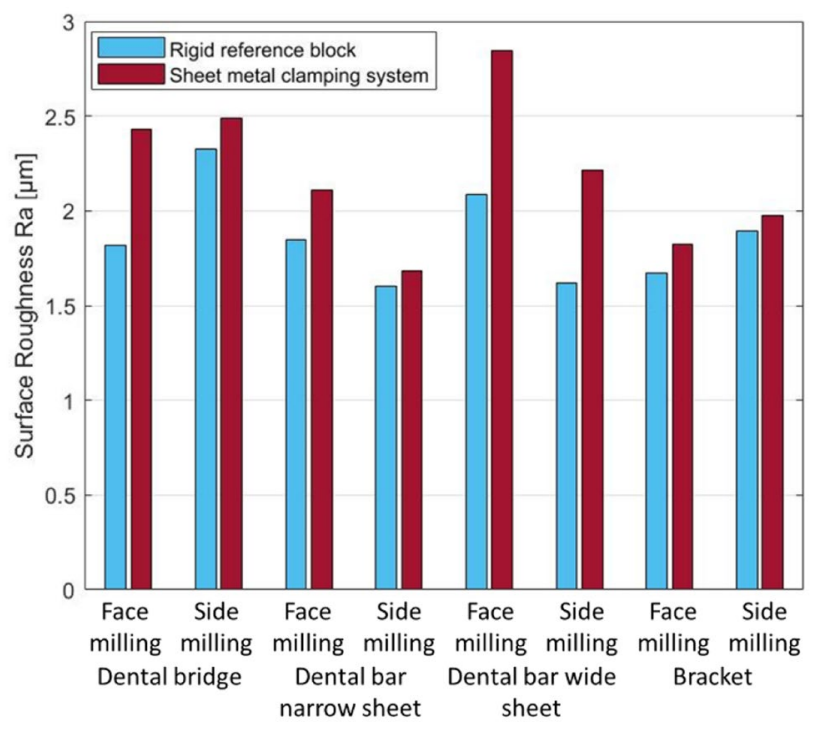

Fig. 22 Measured surface roughness the AM research community, an AM service provider, and machine tool researcher. Figure 25 shows typical clamping solutions for subtractive machining. Zero-point clamping systems maintain a common reference system across different machines [11] and rely on additional interfaces to hold the part. Parallel clamping jaws are the most common clamping system in workshops [12] and require a sufficiently sized flat clamping surface on the part to introduce clamping forces. Form-adaptive clamping jaws use two arrays of clamping pins for a better fit on parts with complex shapes [10]. A bolt clamping system integrates three bolts into the AM part's design and only applies clamping forces to the bolts.

Different quality factors were selected within four categories, as presented in Table 7 . The part characteristics category described specific properties of the LPBF parts that are relevant for post-processing. The design category described the design freedom for the LPBF parts and post-processing. The process category described the milling process's quality that could be performed with a given clamping system. The environment category described the impact on environmental topics. Each factor was then weighted according to the industrial relevance with high relevance: 5 and low relevance: 1 . The ideal clamping system is highly dependent on the LPBF part design and milling effort. Table 7 guides the selection of a suitable clamping solution for a specific application. Compared to other commonly used clamping systems, the sheet metal clamping system has the following main advantages:

1. Applicability to the manufacture of small LPBF parts.

2. LPBF parts can be accessed from the top and bottom.

3. The required additional building height and volume are small.

4. Applicability to mass-scale customization.

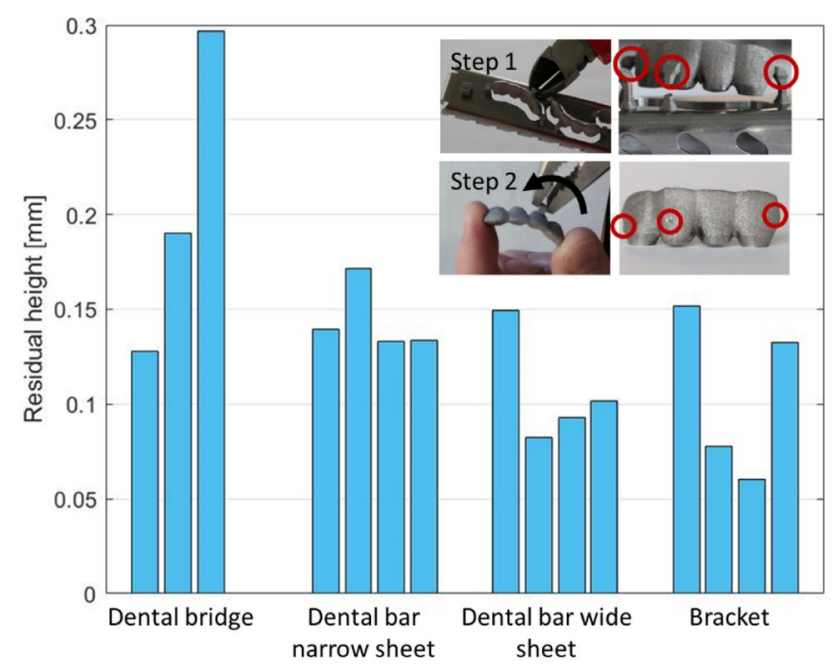

Fig. 23 Residual height after the milling supports were broken off for the different case studies 


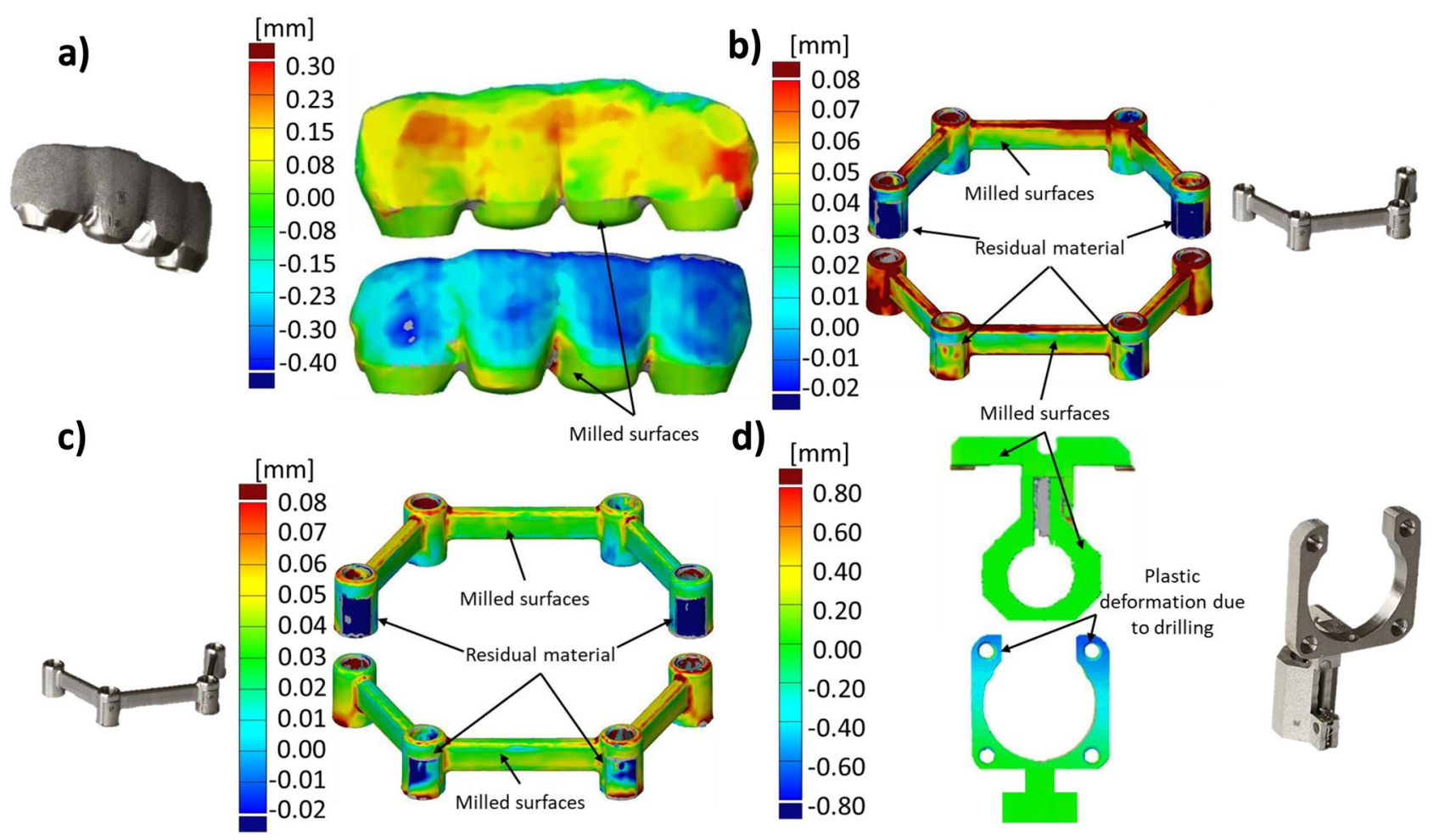

Fig. 24 3D scans of the form deviation: (a) dental bridge, (b) dental bar from narrow sheet, (c) dental bar from wide sheet, and (d) bracket
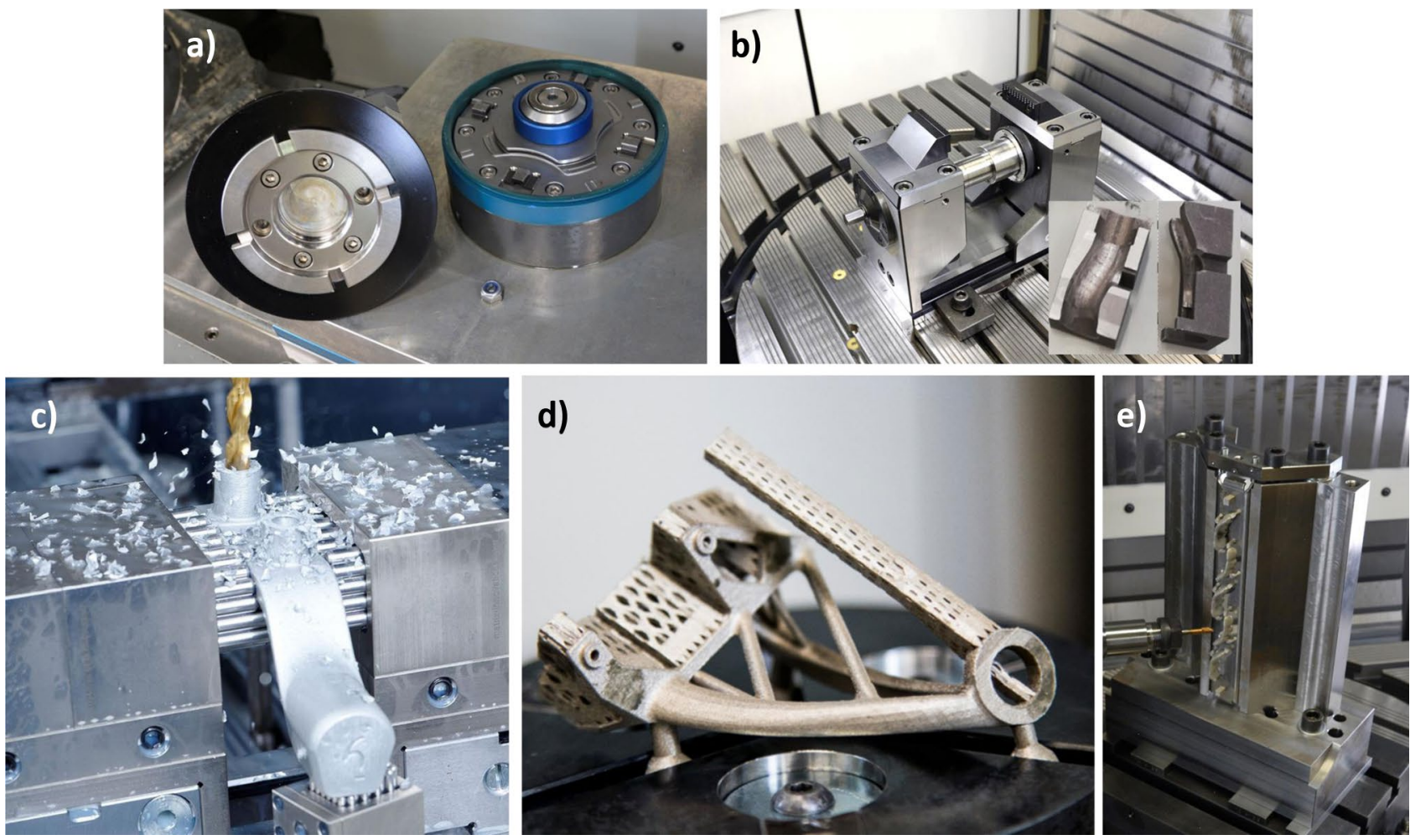

Fig. 25 Typical clamping solutions: (a) zero-point clamping system, (b) parallel clamping jaw, (c) form-adaptive clamping system [26], (d) boltit clamping system, and (e) sheet metal clamping system 
Table 7 Qualitative comparison of different commercial clamping systems for AM

\begin{tabular}{|c|c|c|c|c|c|c|c|}
\hline $\begin{array}{l}\text { Catego- } \\
\text { ry }\end{array}$ & Selection of relevant quality factor & $\begin{array}{l}\text { Level } \\
\text { of } \\
\text { relev } \\
\text { ance }\end{array}$ & $\begin{array}{l}\text { Zero- } \\
\text { point } \\
\text { clamping } \\
\text { system }\end{array}$ & $\begin{array}{l}\text { Parallel } \\
\text { clamping } \\
\text { jaw }\end{array}$ & $\begin{array}{l}\text { Form- } \\
\text { adaptive } \\
\text { clamping } \\
\text { jaw }\end{array}$ & $\begin{array}{l}\text { Bolt } \\
\text { clamping } \\
\text { system }\end{array}$ & $\begin{array}{l}\text { Sheet } \\
\text { metal } \\
\text { clamping } \\
\text { system }\end{array}$ \\
\hline \multirow{8}{*}{$\begin{array}{l}\text { Part } \\
\text { charac- } \\
\text { teristics }\end{array}$} & Fragile thin-walled AM parts & 4 & + & -- & $\approx$ & + & + \\
\hline & Freeform AM parts & 4 & ++ & - & + & ++ & ++ \\
\hline & Round AM parts & 3 & ++ & ++ & - & ++ & ++ \\
\hline & Right angle shaped AM parts & 3 & ++ & ++ & - & ++ & ++ \\
\hline & $\begin{array}{l}\text { Recommended for small AM parts } \\
(<20 \mathrm{~mm})\end{array}$ & 3 & ++ & + & - & $\approx$ & ++ \\
\hline & $\begin{array}{l}\text { Recommended for medium AM } \\
\text { parts }(20-100 \mathrm{~mm})\end{array}$ & 3 & ++ & ++ & ++ & ++ & + \\
\hline & $\begin{array}{l}\text { Recommended for large AM parts } \\
(>100 \mathrm{~mm})\end{array}$ & 2 & ++ & ++ & + & $\approx$ & -- \\
\hline & Massive AM parts & 3 & ++ & ++ & $\approx$ & $\approx$ & -- \\
\hline \multirow[t]{5}{*}{ Design } & High machining accessibility & 5 & + & $\approx$ & -- & ++ & ++ \\
\hline & Design freedom & 4 & - & - & - & ++ & + \\
\hline & Customization & 4 & - & + & + & ++ & ++ \\
\hline & Top/bottom accessibility & 2 & - & $\approx$ & $\approx$ & + & ++ \\
\hline & Side accessibility & 2 & $\approx$ & + & $\approx$ & ++ & $\approx$ \\
\hline \multirow[t]{10}{*}{ Process } & Good surface quality & 4 & + & ++ & + & + & + \\
\hline & High stiffness & 4 & + & ++ & $\approx$ & + & + \\
\hline & Potential for mass customization & 4 & + & - & -- & ++ & ++ \\
\hline & $\begin{array}{l}\text { Potential for series production of } \\
\text { standardized parts }\end{array}$ & 4 & + & + & + & $\approx$ & $\approx$ \\
\hline & Position detection necessary & 3 & + & + & + & + & $\approx$ \\
\hline & Degree of clamping automation & 3 & + & + & + & + & + \\
\hline & Low clamping preprocessing effort & 2 & ++ & - & - & + & + \\
\hline & Low part-induced clamping forces & 1 & ++ & -- & -- & ++ & ++ \\
\hline & No customized tooling & 1 & ++ & $\approx$ & ++ & ++ & ++ \\
\hline & Low support removal effort & 1 & -- & - & - & ++ & ++ \\
\hline \multirow[t]{2}{*}{$\begin{array}{l}\text { Environ- } \\
\text { ment }\end{array}$} & $\begin{array}{l}\text { Low additional interface build } \\
\text { height }\end{array}$ & 2 & ++ & $\approx$ & $\approx$ & -- & ++ \\
\hline & Low material consumption & 2 & + & + & ++ & $\approx$ & $\approx$ \\
\hline
\end{tabular}

$++\hat{=}$ entirely sufficient, $+\hat{=}$ partially sufficient, $\approx \hat{=}$ depending on the application, $-\hat{=}$ limited sufficient, $--\hat{=}$ not sufficient at

\section{Conclusion}

One of the most challenging tasks of LPBF is the complex clamping for milling customized LPBF parts. In this study, a novel and modular sheet metal clamping system was developed that uses disposable sheet metal profiles as a universal interface for LPBF, robotic handling, and milling processes. A parameter set was identified that provides sufficient tensile strength for the machining forces and concept of the sheet metal clamping system. The sheet metal thickness was determined to be the main parameter influencing deformations during the LPBF process. Based on these considerations, the sheet metal clamping system was designed for the LPBF and milling processes, and an end-to-end validation was performed with different case studies. Simulations showed that the sheet metal clamping system enables stable LPBF and milling processes and avoids interruptions. The sheet metal clamping system was then compared with the current state of the art. The following conclusions were drawn:

- The sheet metal clamping system gives milling tools access from five to six sides. This is the first time that an LPBF part can be accessed from the top and bottom sides. Machining of the supported sides of LPBF parts simplifies the removal of LPBF supports. 
- The sheet metal clamping system is robustly designed for the milling process, shown by the frequency response function.

- The sheet metal clamping system is especially applicable to small- and medium-sized parts.

- No additional LPBF build height or material is required.

- No clamping forces are induced in the LPBF part.

- The position detection for the milling process can be automated.

- The milling support structures can be simply removed after the milling process with a minimum residual height.

- The underlying concept of the clamping system enables an economical functional combination of LPBF parts and sheet metals.

The sheet metal clamping system's underlying concept can potentially be applied to automate the LPBF process chain for prosthetic dentistry applications partially. However, more analysis is needed on an entirely automated LPBF process chain's feasibility and mass customization suitability.

Acknowledgements Hanspeter Sauter: ZHAW conceptual consultant. Tobias Fritsche: ZHAW technician for LPBF. Dario Fenner: ETH Zurich technician for milling. Martin Hofer, Fabian Ruf: AM Kyburz

Author contribution Julian Ferchow: conceptualization, methodology, validation, formal analysis, investigation, writing — original draft, visualization, funding acquisition, project administration, project management. Marvin Bühler: conceptualization, methodology, validation, formal analysis, investigation, simulation. Marcel Schlüssel: conceptualization, methodology, formal analysis, investigation, funding acquisition. Livia Zumofen: validation, investigation, formal analysis, writing - review and editing. Christoph Klahn: writing-review and editing. Urs Hofmann: investigation, simulation, writing-review and editing. Andreas Kirchheim: funding acquisition, supervision, writing - review and editing. Mirko Meboldt: writing-review and editing.

Funding Open access funding provided by Swiss Federal Institute of Technology Zurich. The authors thank the Innosuisse for financing this project under grant 35194.1 IP-ENG. Further, the authors would like to thank the Swiss Federal Office of Energy for financing the clamping system workshop (Contract No.: SI/501939-01).

\section{Declarations}

Conflict of interest The authors declare no competing interests.

Open Access This article is licensed under a Creative Commons Attribution 4.0 International License, which permits use, sharing, adaptation, distribution and reproduction in any medium or format, as long as you give appropriate credit to the original author(s) and the source, provide a link to the Creative Commons licence, and indicate if changes were made. The images or other third party material in this article are included in the article's Creative Commons licence, unless indicated otherwise in a credit line to the material. If material is not included in the article's Creative Commons licence and your intended use is not permitted by statutory regulation or exceeds the permitted use, you will need to obtain permission directly from the copyright holder. To view a copy of this licence, visit http://creativecommons.org/licenses/by/4.0/.

\section{References}

1. Attaran M (2017) The rise of 3-D printing: the advantages of additive manufacturing over traditional manufacturing. Bus Horiz 60:677-688. https://doi.org/10.1016/j.bushor.2017.05.011

2. Javaid M, Haleem A (2019) Current status and applications of additive manufacturing in dentistry: a literature-based review. J Oral Biol Craniofacial Res 9:179-185. https://doi.org/10.1016/j. jobcr.2019.04.004

3. Yang H, Rao P, Simpson T, Lu Y, Witherell P, Nassar AR, Reutzel E, Kumara S (2020) Six-sigma quality management of additive manufacturing. Proc IEEE 1-30. https://doi.org/10. 1109/jproc.2020.3034519

4. Almufleh B, Emami E, Alageel O, de Melo F, Seng F, Caron E, Nader SA, Al-Hashedi A, Albuquerque R, Feine J, Tamimi F (2018) Patient satisfaction with laser-sintered removable partial dentures: a crossover pilot clinical trial. J Prosthet Dent 119:560-567.e1. https://doi.org/10.1016/j.prosdent.2017.04.021

5. Silva M, Felismina R, Mateus A, Parreira P, Malça C (2017) Application of a hybrid additive manufacturing methodology to produce a metal/polymer customized dental implant. Procedia Manuf 12:150-155. https://doi.org/10.1016/j.promfg.2017.08.019

6. Gebhardt A, Kessler J, Thurn L (2016) 3D-drucken grundlagen und anwendungen des additive manufacturing (AM), 2nd ed., münchen

7. Deradjat D, Minshall T (2017) Implementation of rapid manufacturing for mass customisation. J Manuf Technol Manag 28:95-121. https://doi.org/10.1108/JMTM-01-2016-0007

8. Oliveira TT, Reis AC (2019) Fabrication of dental implants by the additive manufacturing method: a systematic review. J Prosthet Dent 122:270-274. https://doi.org/10.1016/j.prosdent. 2019.01.018

9. Dilberoglu UM, Gharehpapagh B, Yaman U (2021) Current trends and research opportunities in hybrid additive manufacturing. Int J Adv Manuf Technol 113:623-648. https://doi.org/ 10.1007/s00170-021-06688-1

10. Bi ZM, Zhang WJ (2001) Flexible fixture design and automation: review, issues and future directions. Int J Prod Res 39:2867-2894. https://doi.org/10.1080/00207540110054579

11. Sitzberger S, Liebl J, Reitberger J, Rascher R (2019) Zero-point clamping systems in optical production. Proc SPIE. https://doi. org/10.1117/12.2528774

12. Bai J, Kai Y (2014) Development of an ontology for the automatic selection of control valves. Proc ASME Des Eng Tech Conf 1B:1-11. https://doi.org/10.1115/DETC201434792

13. Klahn C, Omidvarkarjan D, Meboldt M (2018) Evolution of design guidelines for additive manufacturing - highlighting achievements and open issues by revisiting an early SLM aircraft bracket. Ind Addit Manuf Proc Addit Manuf Prod Appl AMPA 2017 3-13. https://doi.org/10.1007/978-3-319-66866-6

14. Durakovic B (2018) Design for additive manufacturing: benefits, trends and challenges. Period Eng Nat Sci 6:179-191. https:// doi.org/10.21533/pen.v6i2.224

15. Schaub A, Juechter V, Singer RF, Merklein M (2014) Characterization of hybrid components consisting of SEBM additive structures and sheet metal of alloy Ti-6Al-4V. Key Eng Mater 611-612:609614. https://doi.org/10.4028/www.scientific.net/KEM.611-612.609

16. O’Regan P, Prickett P, Setchi R, Hankins G, Jones N (2016) Metal based additive layer manufacturing: variations, correlations and process control. Procedia Comput Sci 96:216-224. https://doi.org/10.1016/j.procs.2016.08.134

17. Schaub A, Ahuja B, Butzhammer L, Osterziel J, Schmidt M, Merklein M (2016) Additive manufacturing of functional elements on sheet metal. Phys Procedia 83:797-807. https://doi. org/10.1016/j.phpro.2016.08.082 
18. Li C, Liu ZY, Fang XY, Guo YB (2018) Residual stress in metal additive manufacturing. Procedia CIRP 71:348-353. https://doi. org/10.1016/j.procir.2018.05.039

19. Siqueira RHM, Carvalho SM, Kam IKL, Riva R, Lima MSF (2016) Non-contact sheet forming using lasers applied to a high strength aluminum alloy. J Mater Res Technol 5:275-281. https://doi.org/10.1016/j.jmrt.2016.02.002

20. Rashid R, Masood SH, Ruan D, Palanisamy S, Rashid RR, Elambasseril J, Brandt M (2018) Effect of energy per layer on the anisotropy of selective laser melted AlSi12 aluminium alloy. Addit Manuf 22:426-439. https://doi.org/10.1016/j.addma. 2018.05.040

21. Stoll P, Spierings A, Wegener K (2019) Impact of a process interruption on tensile properties of SS 316L parts and hybrid parts produced with selective laser melting. Int J Adv Manuf Technol 103:367-376. https://doi.org/10.1007/s00170-019-03560-1

22. Merklein M, Schulte R, Papke T (2021) An innovative process combination of additive manufacturing and sheet bulk metal forming for manufacturing a functional hybrid part. J Mater
Process Technol 291:117032. https://doi.org/10.1016/j.jmatp rotec. 2020.117032

23. Schaub A (2018) Grundlagenwissenschaftliche Untersuchung der kombinierten Prozesskette aus Umformen und Additive Fertigung. FAU University Press, Erlangen. https://doi.org/10. 25593/978-3-96147-167-6

24. Lin WS, Chou JC, Metz MJ, Harris BT, Morton D (2015) Use of intraoral digital scanning for a CAD/CAM-fabricated milled bar and superstructure framework for an implant-supported, removable complete dental prosthesis. J Prosthet Dent 113:509-515. https://doi.org/10.1016/j.prosdent.2015.01.014

25. DIN ISO 1101 (1985) Form-und Lagetolerierung, Beuth: Berlin

26. MATRIX GmbH Spannsysteme und Produktionsautomatisierung, Form adaptive clamping system. https://www.matrix-innovations. de/daimler-silver-clamp/ (accessed 15 Mar 2021)

Publisher's note Springer Nature remains neutral with regard to jurisdictional claims in published maps and institutional affiliations. 